\title{
PERSONAL, NUTRITIONAL AND HABITUAL RISK FACTORS RELATED TO OSTEOPOROSIS OF FEMALE EMPLOYEES AND STUDENTS AT KING FAISAL UNIVERSITY, AL-HASSA PROVINCE, KINGDOM OF SAUDI ARABIA
}

(Received: 8.8.2017)

\author{
By \\ N. A. Alabbad \\ Department of Food and Nutrition Sciences, College of Agricultural and Food Sciences, \\ King Feisal University, Kingdom of Saudi Arabia
}

\begin{abstract}
Osteoporosis is a chronic disease in the Arab countries. It is called the "silent disease", and caused by several factors such as aging, certain nutritional factors, and physical inactivity. The aim of this study was to monitor the personal, nutritional and life risk factors associated with osteoporosis in the students and employees of King Faisal University in Al-Hassa Province, Eastern Saudi Arabia. The descriptive analytical approach was used and data collected using self-administered survey, which included information such as age, level of nutritional knowledge, social, economic status and place of residence, as well as some health practices and frequency of certain foods that protect from or cause osteoporosis. The sample included 100 volunteer female employees and 510 female students, from three colleges in the University. Data were analyzed by the statistical program SPSS, ver. 17. The results showed that the level of nutritional knowledge among most female University students was medium (70.7\%). The results also showed that both the employees and students of the university have personal, nutritional and life risk factors that might, increase their risk in the future, and the number of risk factors for the University employees higher when compared to the students. The risk factors for the University employees included: aging, physical inactivity (72\%), exposure to sunlight (53\%), passive smoking (46\%) (One or more smoker in the family), whereas the risk factors for the female students, included: physical inactivity $(62.4 \%)$, and passive smoking (48.2\%). The results also showed that both students and employees had nutritional risk factors such as inadequate intake of milk and dairy products, high intake of fatty red meat, salted foods and soda drinks which might increase the risk of osteoporosis. Students and employees ate adequate amounts of fatty fish, green leafy vegetables, citrus fruits and nuts that protect against osteoporosis. Based on the results, the study recommends that the students and employees should pay attention to balanced nutrition, have sufficient amounts of food that protect against osteoporosis, avoid food that increase the risk of osteoporosis, as well as practicing a healthy life style such as physical activity, exposure to the sunlight and avoid contact with smokers. It is also proposed that, the University administration organize nutrition education programs to raise awareness of the importance of good nutrition and health practices.
\end{abstract}

Key words: Osteoporosis, Osteoporosis risk factors, Food frequency, Nutritional knowledge, Female college employees and students, Kingdom of Saudi Arabia. 


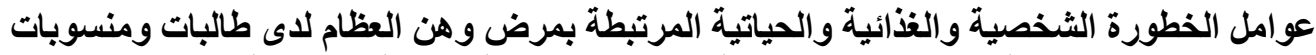 جامعة الملك فيصل بمحافظة الإحساء- المملكة العربية السعودية العزية
}

\section{نجاة علي العباد}

قسم علوم الغذاء و التغذية بكلية العلوم الزر اعية والأغذية ــ جامعة الملك فيصلـ المملكة العربية السعودية

\begin{abstract}
ملخص الخص

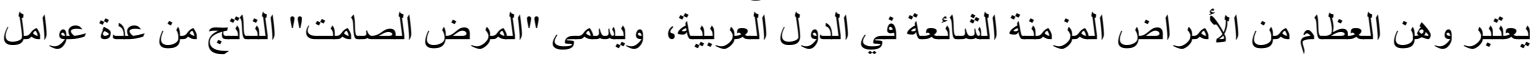

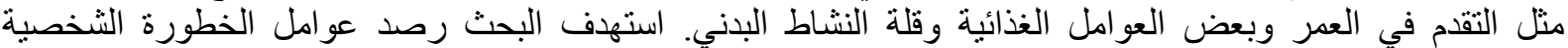

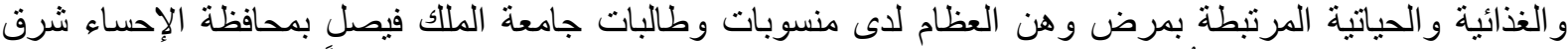

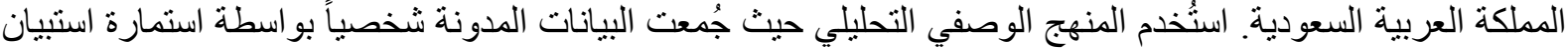

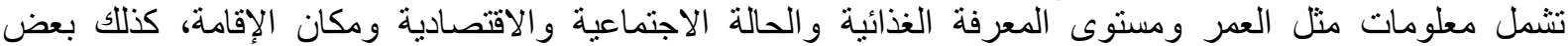

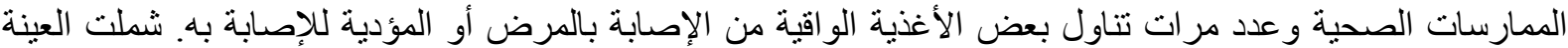

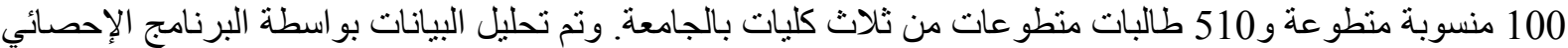
(SPSS, ver. 17)

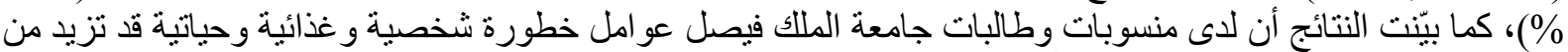

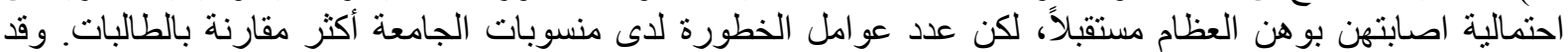

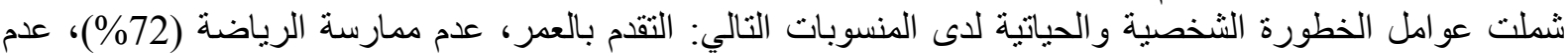

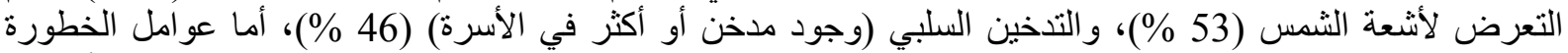

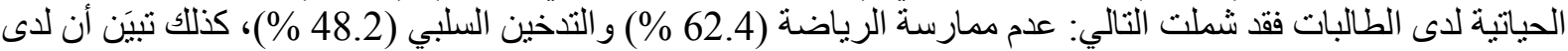

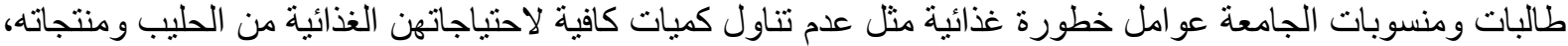

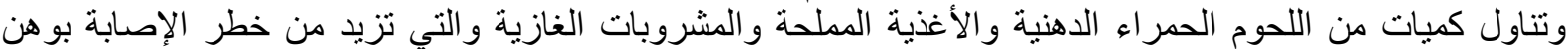

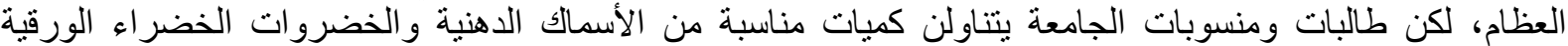

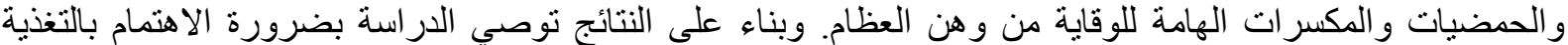

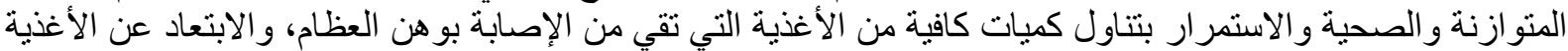

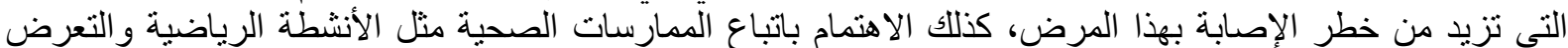

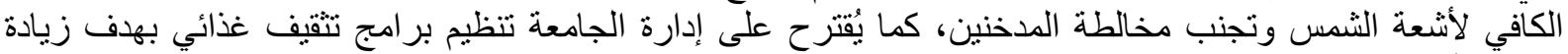
الو عي بأهمية التغذية الجيدة و الممارسات الصحية.

(Hannan et al.,2000)

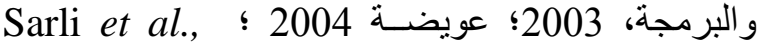

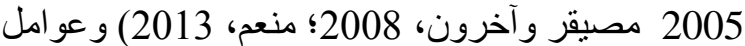
هرمونية (أبو المكارم وآخرون، 2007 آلإنة

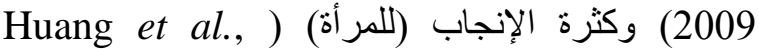
1996) وقلة التعرض لأشعة الثمس (المدني، 2004)

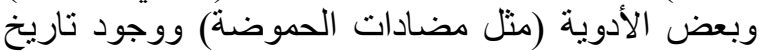

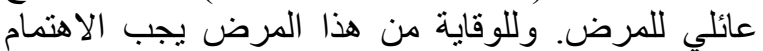
بالتغذية المتوازنة وتناول كميات كافية من البراتية البروتينات

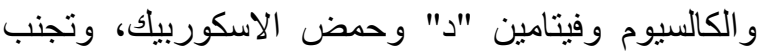
الإكثار من الأغذية المملحة والمنبرة ولبهات (الغنية بالكافين)

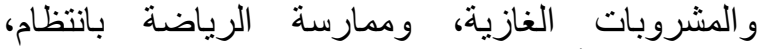

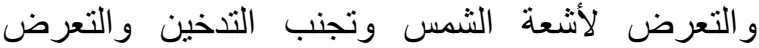
اللتدخين السلبي، ويتم علاج المصابين بو هن العظام بالعلاج

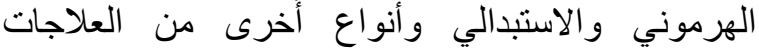

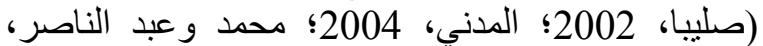

وتُشبر الأبحاث التي أُجريت في بعض الدول العربية إلى العى

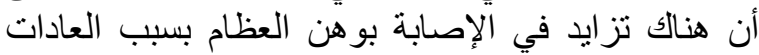
الغذائية والصحية الخاطئة و التغير في نمط الإنية الحياة (مصيقر وآخرون، 2008)، ففي الخمس عقود الأخيرة حدثت

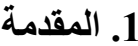

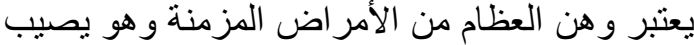
ملايين البشر حول العالم، ويُشير إلى نقص الكتير الكتلة العظمية

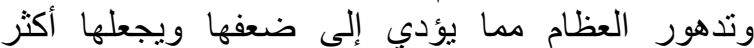

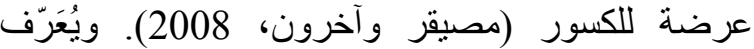

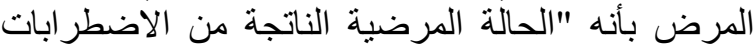
التي تُصيب الهيكل العظمي، و التي تقل فيها كثافة العظام

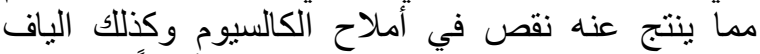

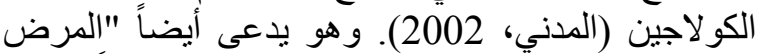

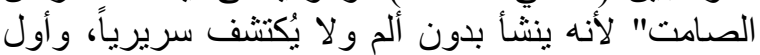

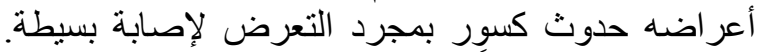
ويحدث 90 \% تقريباً من نمو العظام في الفترة العمرية ما لها بين 10 - 20، لذا كلما زادت كثنافة العظام في هذه الفت الفترة

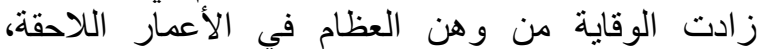
وبالرغم من أن العوامل الور الثية تحدد 70 - 80 \%

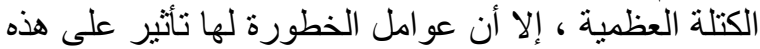

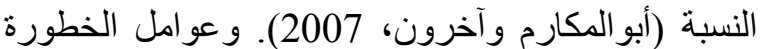
تتضمن التقدم في العمر والجنس (النساء أكثر عرضية

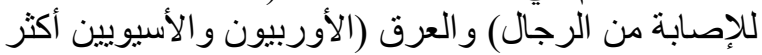

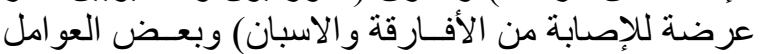

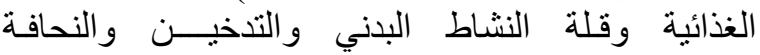


التغذية والممارسات الحياتية وممارسة الرياضة إيجابية.

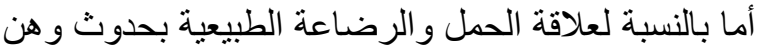

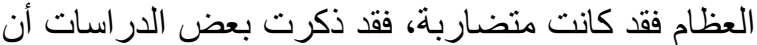

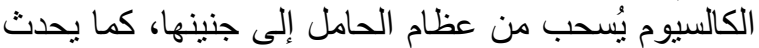

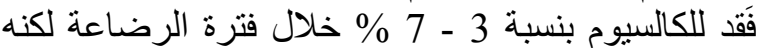

يُعوضنّ بسر عة بعد الفطام

(Kalkwarf and Specker, 2002؛ Kalkwarf, 2004 ؛ Karlsson et al., 2005 ؛ Kovacs, 2005) ،

فمن النادر إصابة المرأة بهذا المرض بسبب الحمل الحمل

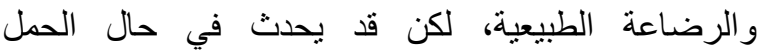

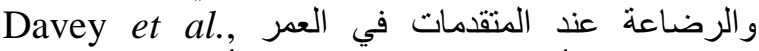

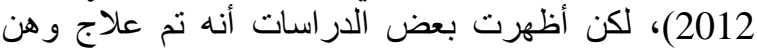

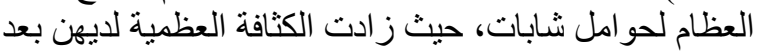
سنتين من العلاج بالكالسيو و وفيتامين "د" وبعض العناتئ الأدوية. (Di Gregorio et al., 2000؛ Aynaci et al., 2008 ؛O'Sullivan et al., 2006)

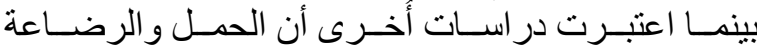

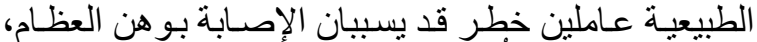

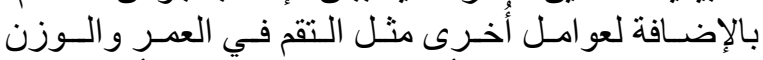

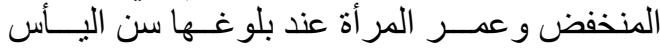

(Ruiz-Irastorza et al., 2002 ؛ Grimes and Wimalawansa, 2003 ؛ Pearson et al., 2004 ؛ Dursun et al., 2006).

وتأتي أهمية البحث بسبب ارتفاع نسبة الإصابة بوهن المنا

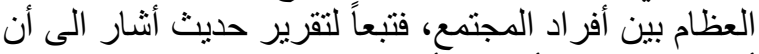

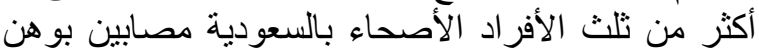

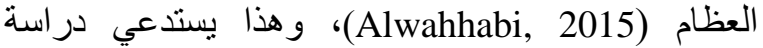

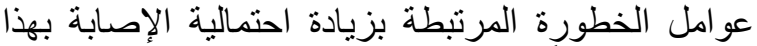

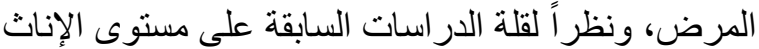

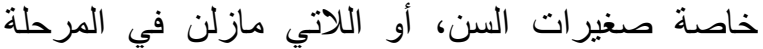

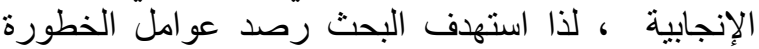

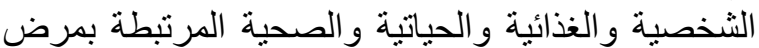

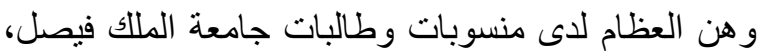

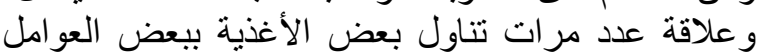

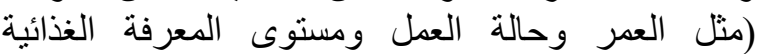
المرتبطة بوهن العظام)، و الاستفادة من نتائج الدراسة في في

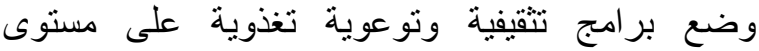

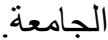

\section{2. طريقة الاراسة وإجراء|تها

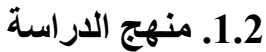 \\ تم استخدام المنهج الوصفي التحليلي لملائمته للار اسة

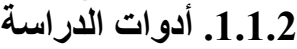
- تم إعداد استبيان يتضمن أسئلة عامة عن المنة المنسوبات

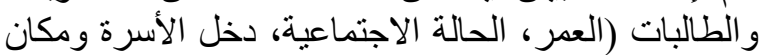

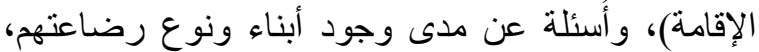
وأسئلة عن بعض الممارسات الصحية (مستوى النشاط وندئ

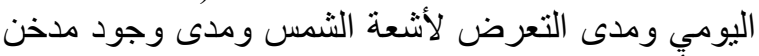

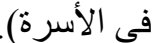

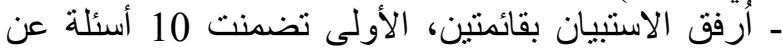

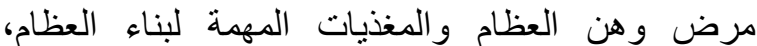

تغير ات عديدة في الوضع الاجتماعي و الاقتصادي، و انتشر

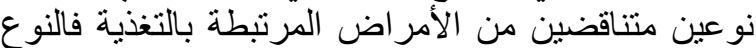

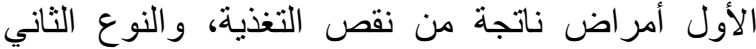
أمراض ناتجة من التغيرات في التئ الممارسات الغذائية

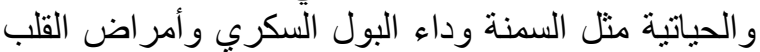

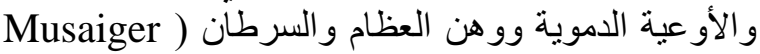
Sadat-Ali et al. (2005) وقد (et al., 2011 أن 50 - 60 \% من النساء السعوديات معرضات للإِصابة

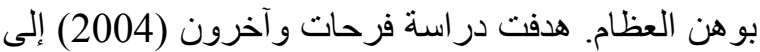
التعرف على مسبيات إصابة نساء بو هن العنات العظام مقارنة بنساء غير مصابات في القاهرة، فاستخلصو التهاء بأن لممارسة الأنشطة الحياتية وممارسة الرياضة تأثانثير في كثافة العظام،

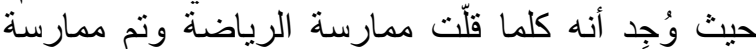
سلوكيات خاطئة مثل التدخين، كلما انخفضت كثات كثافة الكنلة

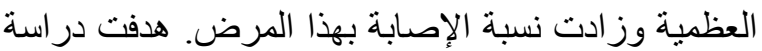

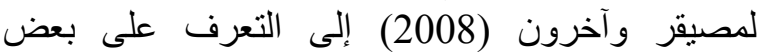

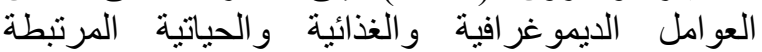
بالإصـابة بو هن العظام لدى البالغين في البحرين (بعمر بين

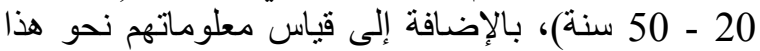
المرض وأوضحت النتائج عدم تناول 25 \% 25 من من النساء

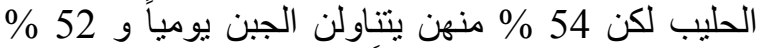

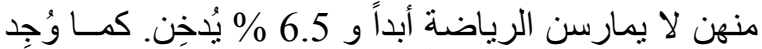

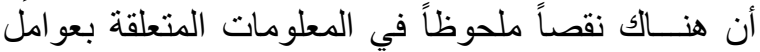

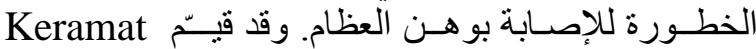
عو امل الخطورة لإير انيات عمر هن أكبر

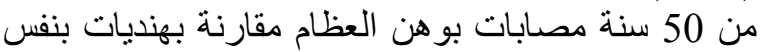

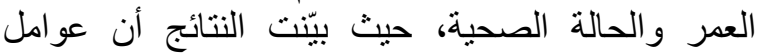

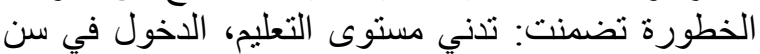

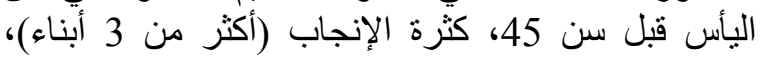

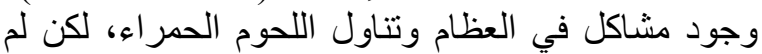

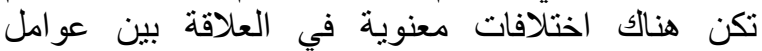
الخطورة ووهن العظام بين الإيرانيات و الهنديات. كما فيّم Kartikey et al. (2010) الأحماض الدهنية من نوع اوميغا-6: اوميغا-3 في الغئ الوجية

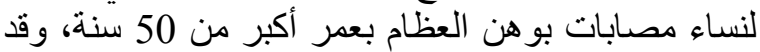

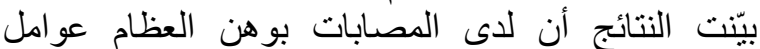

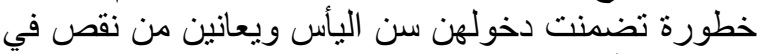

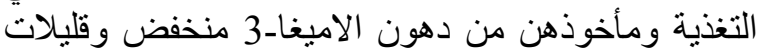
النشاط البدني مقارنة بالمجمو عة دهن القياسية (أصحاء). بيّنت

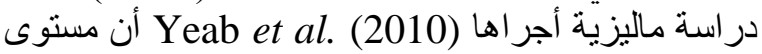
المعرفة الغذائية المرتبطة بوهن العالية العظام لأغلب النساء

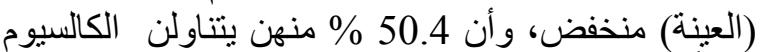

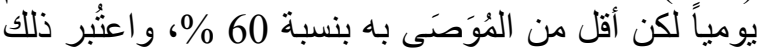

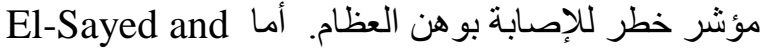
Abdel Megeid (2013)

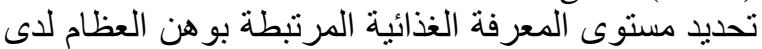

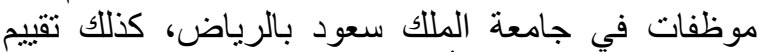

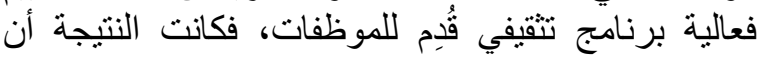

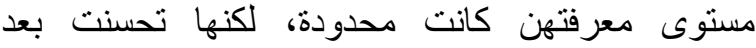
حضورهن البرنامج التثقيفي، كما أصبحت اتجاهاتهن نحو 
واختبـار التبـاين الأحسادي (ANOVA) لدر اســة معنويـة

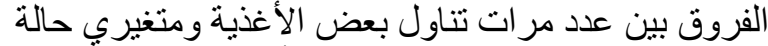

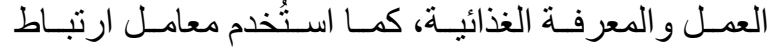

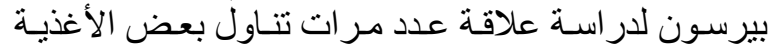

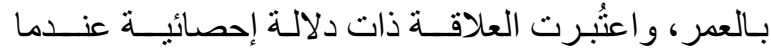

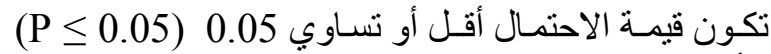
( أبوسريع، 2004).

\section{3. - 3. النتائج والمناقشة}

أوضح التحليل الإحصائي النتائج التالي

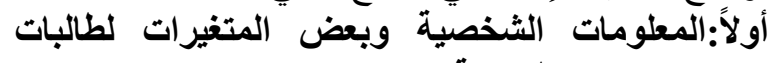
ومنسوبات الجامعة الامومات

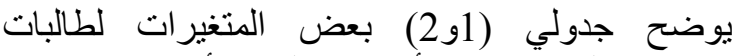
ومنسوبات الجامعة، وقد أظهرت النتائج أن متوسط عمر النير

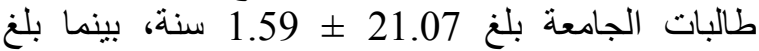

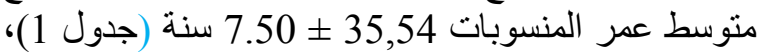
كما وُجدد أن 65.1 \% من من الطالبات غير متزوجات

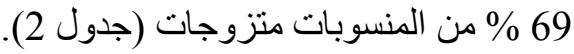

جدول (1) : عمر طالبات ومنسوبات الجامعة (المتوسط الانحراف المعياري).

\begin{tabular}{|c|c|c|}
\hline المنسوبات & الطالبات & \multirow{2}{*}{ العمر (سنة) } \\
\hline $7.50 \pm 35.54$ & $1.59 \pm 21.07$ & \\
\hline 20 - 57 سنة & 17 - 28 سنة & أقل وأكبر عمر (المدى) \\
\hline
\end{tabular}

أظهرت النتائج في الجدول (2) أن أغلب طالبات

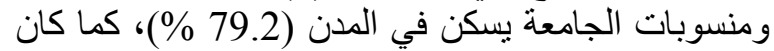
دخل أسر المنسوبات أعلى مقارنة بأسر الطالبات، فقد بلغ كان

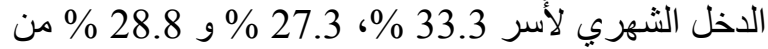

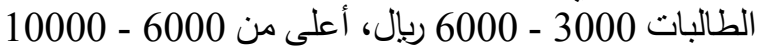
ربال و أعلى من 10000 ربإل على التو الي، التي بينما بلغ الدخل الثهري لأسر أغلب منسوبات الجامعة أعلى من ربال (76 \% \%).
و الأغذية الني تقي من الإصابة بالمرض أو تسببه و عو امل

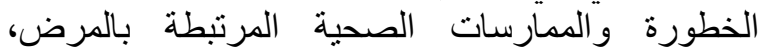
و واستخدمت هذه القائمة لتحديد مستوى المعرفة الغذائية، ووضع اختبارين للإجابة (نعم، لانة) وتم تقدير الإجابة الإنة

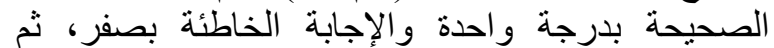
صُنفت الدرجات إلى ثنلاث مستويات، مستوى معرفة غذائية منخفض لمن تتحصل عند على 5 درجات أو أو أقل

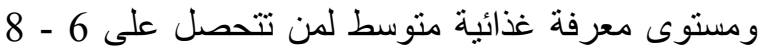

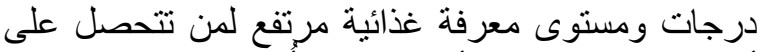

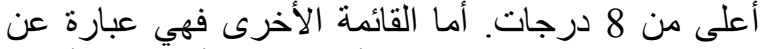
استمارة تكرار تناول بعض الأغذية في الأسبوع (الأغذية الأبية

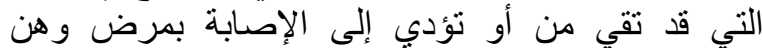
العظام)، وقد اعدت الباحثة هاتين القائمنين من أدبيات

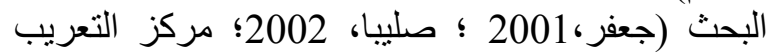
و البرمجة، 2003؛ المدني، 2004؛ المغ 2004؛ المدني، 2005؛ المركز العربي للتغذية، 2006؛ المراسي وعبد المجيد،

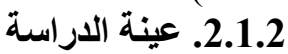
تم توزيع استمارة الاستبيان على عينة الدراسة بواسة اسطة

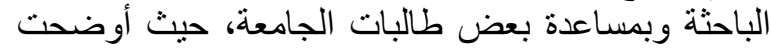

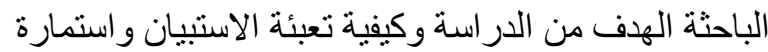
تكرار تناول الطعام. وقد بلغ الغة عدد العينة (اللاتي قبلن

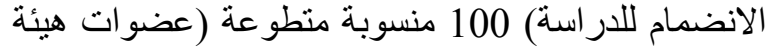

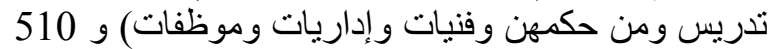

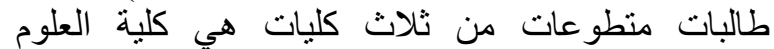
الزر اعية و الأغذية و التربية و العلوم ، ونم جمع البئ البيانات في هي الفترة من سبتمبر حتى نوفمبر سنة 2015 م.

3.1.2. 3. 3. التحاليل الإحصائية

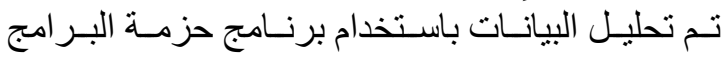

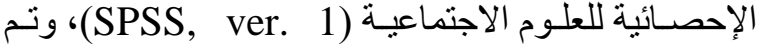

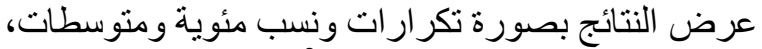

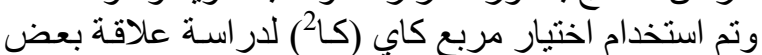

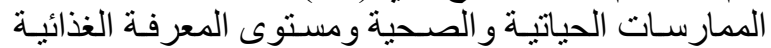
بحالة العمل (طالبة، منسوبة) واستُخدم اختبار ت (t-test)

جدول (2) : بعض المتغيرات لطالبات ومنسويات الجامعة.

\begin{tabular}{|c|c|c|c|c|c|c|c|}
\hline \multicolumn{2}{|c|}{ المجموع } & \multicolumn{2}{|c|}{ المنسوبات } & \multicolumn{2}{|c|}{ الطالبات } & \multirow{2}{*}{\multicolumn{2}{|c|}{ المتغير }} \\
\hline$\%$ & عدد & $\%$ & عدد & $\%$ & عدد & & \\
\hline 58.3 & 356 & 24.0 & 24 & 65.1 & 332 & غير متزوجة & \\
\hline 39.7 & 242 & 69.0 & 69 & 33.9 & 173 & متزوجة & 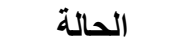 \\
\hline 2.0 & 12 & 7.0 & 7 & 1.0 & 5 & أرملة ـ مطلقة & الاجتماعية \\
\hline 100 & 610 & 100 & 100 & 100 & 510 & المجموع & \\
\hline 79.2 & 483 & 84.0 & 84 & 78.2 & 399 & المدينة & \\
\hline 20.8 & 127 & 16.0 & 16 & 21.8 & 111 & القرية & مكان الإقامة \\
\hline 100 & 610 & 100 & 100 & 100 & 510 & المجموع & \\
\hline 6.9 & 42 & 7.0 & 7 & 6.9 & 35 & أقل من 3000 & \\
\hline 30.7 & 187 & 17,0 & 17 & 33.3 & $\mathbf{1 7 0}$ & $6000-3000$ & \\
\hline 28.3 & 173 & 34.0 & 34 & 27.3 & 139 & أعلى من 6000 -10000 & 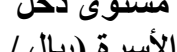 \\
\hline 31.0 & 189 & 42.0 & 42 & 28.8 & 147 & أعلى من 10000 & \\
\hline 3.1 & 19 & 0.0 & $\mathbf{0}$ & 3.7 & 19 & غير محدد- غير معروف & \\
\hline 100 & 610 & 100 & 100 & 100 & 510 & المجموع & \\
\hline
\end{tabular}


ضمن ثلاث اختيارات: نشاط خفيف (مثل الجلوس معظم اليوم والعمل المكتبي والمشي البطيء) ونشئ ونشاط منوسط (مثل مهنة التدريس و المشي السريع) ونشاط شاق الهئ (مثل

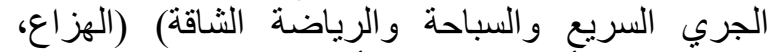
2004)، وقد أظهرت النتائج أن مستوى النشاطي النشاط اليومي

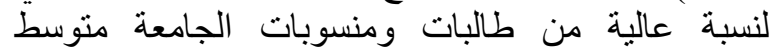

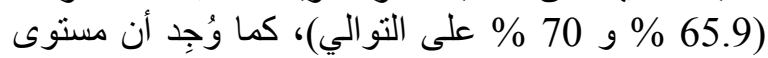

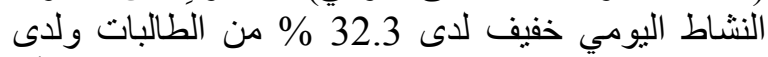
29 \% من المنسوبات (P > P) (P)، بالإضافة إلى أن
أظهرت النتائج في جدول (3) أن هناك فروق معنوية

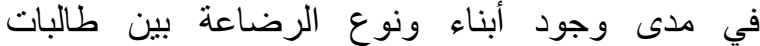

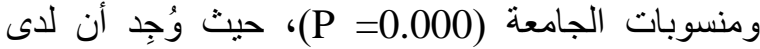

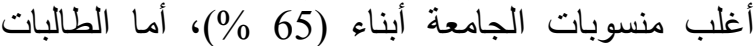

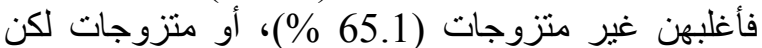

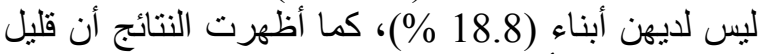

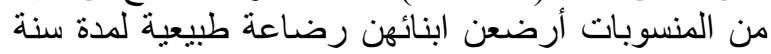

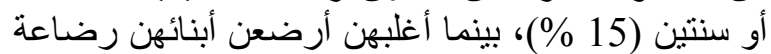
مختلطة (43 \%)، وقد يكون السبب ارتباطهن بالعمل.

جدول (3): مدى وجود أبناء لدى طالبات ومنسويات الجامعة ونوع رضاعة الأبناء.

\begin{tabular}{|c|c|c|c|c|c|c|c|}
\hline \multicolumn{2}{|c|}{ المجموع } & \multicolumn{2}{|c|}{ المنسوبات } & \multicolumn{2}{|c|}{ الطالبات } & \multirow{2}{*}{ 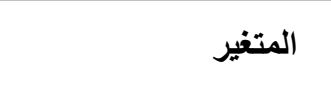 } & \\
\hline عدد ( عد & $\%$ & عدد & عدد & $\%$ & عدد & & \\
\hline 24.1 & 147 & 65.0 & 65 & 16.1 & 82 & نعم & \multirow{4}{*}{ مدى وجود أبناء** } \\
\hline 17.5 & 107 & 11.0 & 11 & 18.8 & 96 & ע & \\
\hline 58.4 & 356 & 24.0 & 24 & 65.1 & 332 & غير متزوجة & \\
\hline 100 & 610 & 100 & 100 & 100 & 510 & المجموع & \\
\hline \multicolumn{7}{|c|}{ *قيمة كام = 110.148 (P=000) } & \multirow{8}{*}{ نوع الرضاعة*** } \\
\hline 2.1 & 13 & 6.0 & 6 & 1.4 & 7 & رضاعة طبيعية لمدة سنتين & \\
\hline 2.8 & 17 & 9.0 & 9 & 1.6 & 8 & رضاعة طبيعية لمدة سنة & \\
\hline 15.6 & 95 & 43.0 & 43 & 10.2 & 52 & رضناعية مختلطة (طبيعية & \\
\hline 3.6 & 22 & 7.0 & 7 & 2.9 & 15 & رضاعة صناعية & \\
\hline $\mathbf{1 7 . 5}$ & 107 & 11.0 & 11 & 18.8 & 96 & متزوجة ليس لايها أطفال & \\
\hline 58.4 & 356 & 24.0 & 24 & 65.1 & 332 & غير متزوجة & \\
\hline 100 & 610 & 100 & 100 & 100 & 510 & المجموع & \\
\hline
\end{tabular}

أغلب الطالبات و المنسوبات لا يمارسن أي نشاط رياضي

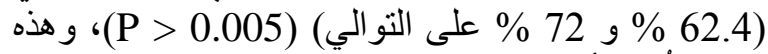
النتائج تُشير أن تلك الفئات من الطالبات و المنسو

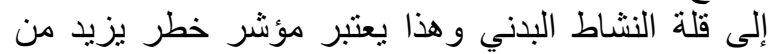

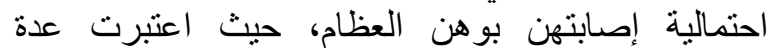

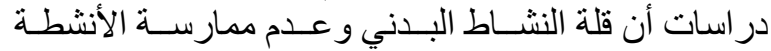

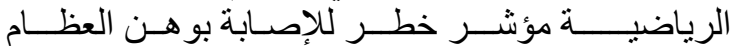
(Cohen and Roe, 2000 ! VonHurst and Wham, 2007 ! Kartikey et al. 2010).

أما در اسة الهز اع (2004) فقد أكدت على أهمية النشاط

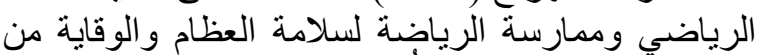

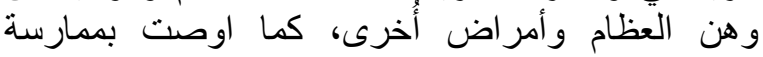

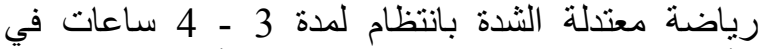

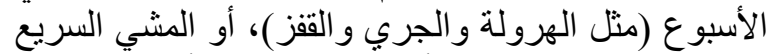

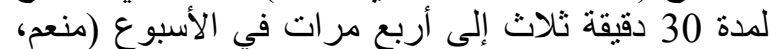

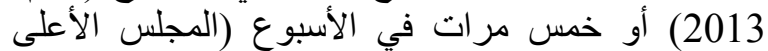

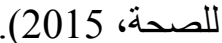
أظهرت النتائج أيضاً أن 56.1 \% من طالبات الجامعة

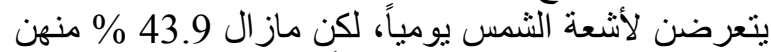

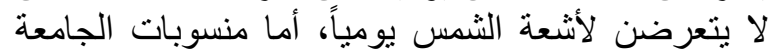

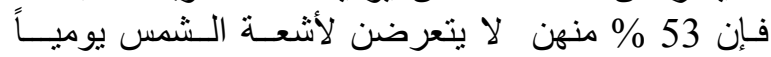

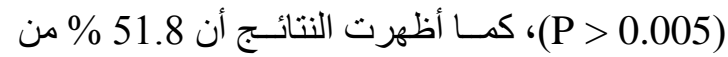

ثُبيّن النتائج في الجدول (3) أيضاً أن عينة الدراسة ليس

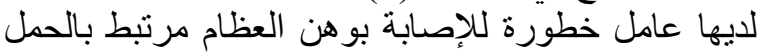

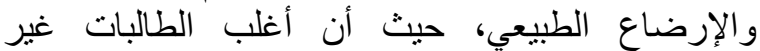

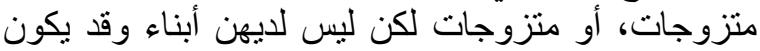

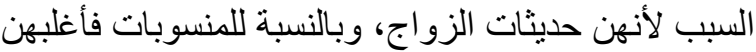

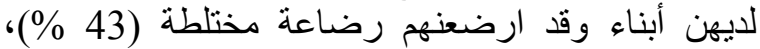
وقليل منهن أرضعن ابنائهن رضاعة رضاعة صناعية أو رضاعة أنة طبيعية لمدة سنة أو سنتين. بالر غم من أن هذه النتائج قد تعني عدم وجود خطورة

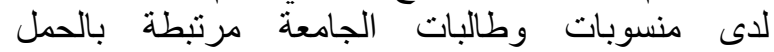

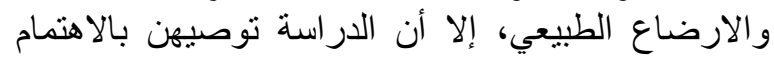

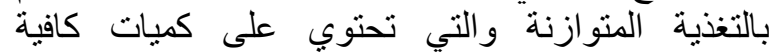
بالمغذيات اللازمة لقوة وسلامة العظام. فتنتاول الإنات

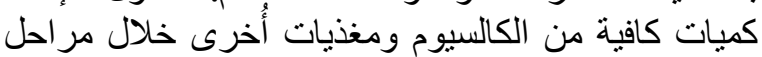

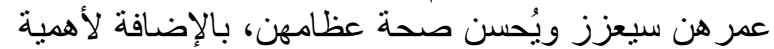
و عيهن بتناول كميات كافية من الكالسيوم وفيتامين بالافين لاهين

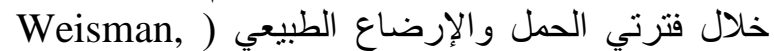
2005 ثانياً: بعض المضارسات الصحية لطالبات ومنسوبات الجامعة البفة

عند سؤال عينة الدراسة عن مستوى نشاطهن البدني اليومي، طلب منهن اختيار مستوى النشاط المناسب لئن لهن البن 


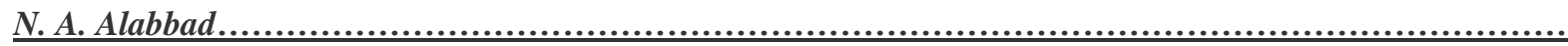

جدول (4): بعض الممارسات الصحية لطالبات ومنسويات الجامعة.

\begin{tabular}{|c|c|c|c|c|c|c|c|}
\hline \multicolumn{2}{|c|}{ المجموع } & \multicolumn{2}{|c|}{ المنسويات } & \multicolumn{2}{|c|}{ الطالبات } & \multirow{2}{*}{\multicolumn{2}{|c|}{ ال المتغير }} \\
\hline عدد & $\%$ & عدد & عدد & $\%$ & عدد & & \\
\hline 31.8 & 194 & 29.0 & 29 & 32.3 & 165 & خفيف & \\
\hline 66.6 & 406 & 70.0 & 70 & 65.9 & 336 & متوسط & \\
\hline 1.6 & 10 & 1.0 & 1 & 1.8 & 9 & شاق & \\
\hline 100 & 610 & 100 & 100 & 100 & 510 & المجموع & \\
\hline 36.1 & 220 & 28.0 & 28 & 37.6 & 192 & 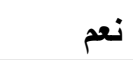 & \\
\hline 63.9 & 390 & 72.0 & 72 & 62.4 & 318 & ע & ممارسة الأنشطة الرياضية \\
\hline 100 & 610 & 100 & 100 & 100 & 510 & المجموع & \\
\hline 54.6 & 333 & 47.0 & 47 & 56.1 & 286 & ن معم & \\
\hline 45.4 & 277 & 53.0 & 53 & 43.9 & 224 & ע & التعرض لأثشعة الثمس يومياً \\
\hline 100 & 610 & 100 & 100 & 100 & 510 & المجموع & \\
\hline 47.9 & 292 & 46.0 & 46 & 48.2 & 246 & 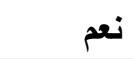 & \\
\hline 52.1 & 318 & 54.0 & 54 & 51.8 & 264 & ע & وجود مدخن أو أكثر في الأسرة \\
\hline 100 & 610 & 100 & 100 & 100 & 510 & المجموع & \\
\hline
\end{tabular}

(الفروق بين الطالبات والمنسوبات غير معنوية (P > 0.05)

نتائج الدراسة تو افقت مع بعض نتائج الدراسات السابقة

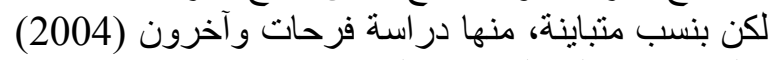

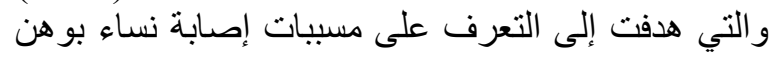
العظام مقارنة بنساء غير مصابات في القاهرة، والت وقد بيّنت النتائج أن 63.3 \% من المصابات غئرة (بوهن العظام) يمارسن

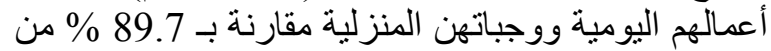

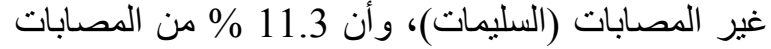
يمارسن رياضة المشي بانتظام مقارنة بـ 23.2 \% \% من

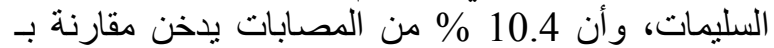

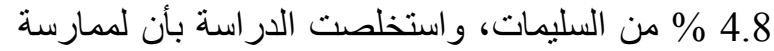

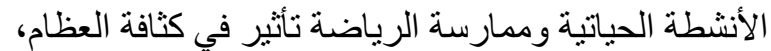

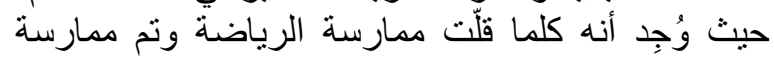

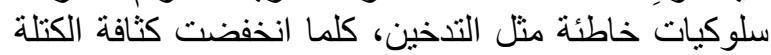

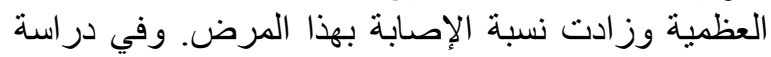

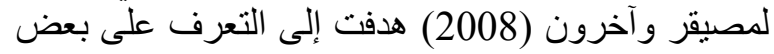

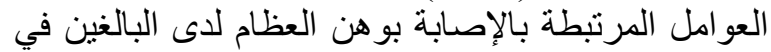

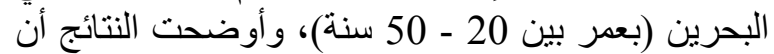
20.3 \% و 27.7 \% \% 27 \% من البحر انيات بمارسن الرياضة غالباً و أحياناً وأن 52 \% \% منهن لا يمارسن الرياضة أبداً و و و

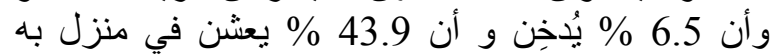

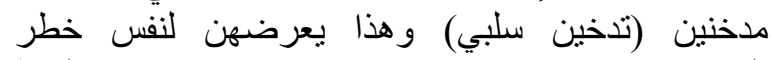

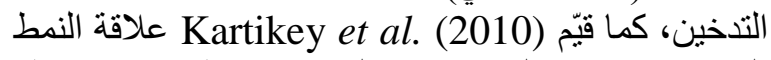

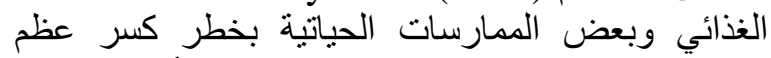
الحوض لنساء مصابات بوهن العنات العظام بعمر أكبر من 50
الطالبات و54 \% من المنسوبات لا يتعرضن للتنخين

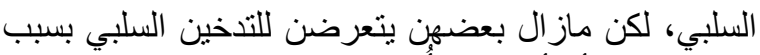

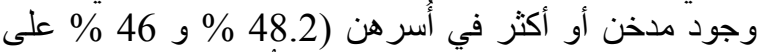

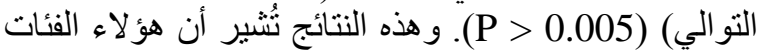

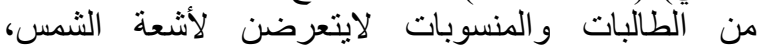
ويتعرضن لتأثير التدخين السلبي، ويعتبر هاذين العانئن العاملان

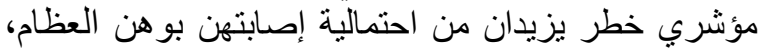
حيث اعتبرت عدة دراسات التدخين (الإيجابي و السلبي) وعدم التعرض لأشعة الثمس مؤشري خطر للإِ لإصابة

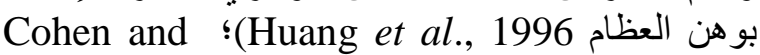
Mithal et al., 2009 ؛ Roe, 2000 ؛ 2002 منعم، 2013)، ويُعتقد أن التدخين يؤثر سلباً في الخلايا

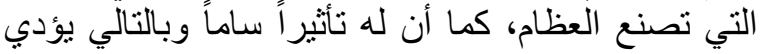

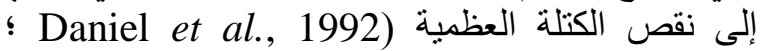

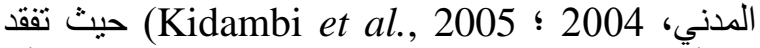

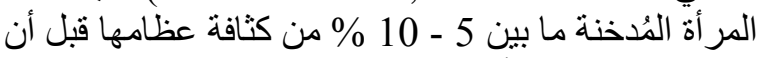

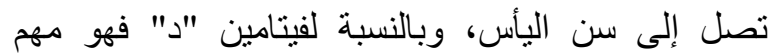

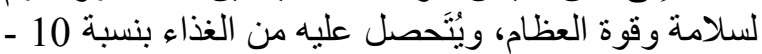

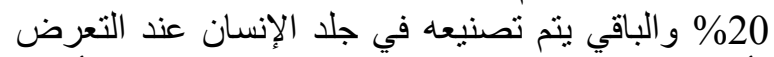

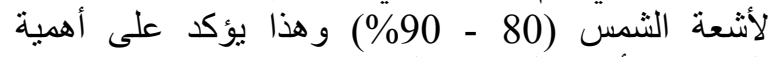

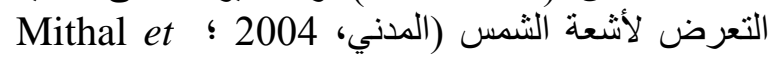

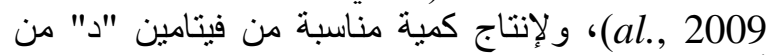

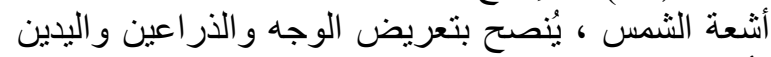

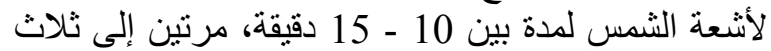
مر ات أسبو عياً (مركز التعريب و البرمجة، 2003) مدينة 
Yeab et al. (2010) و

Whaba et al. (2010) Al-Shahrani et al. (2010) بيّنت أن مستوى المعرفة الغذائية المرتبطة بوهن العظام

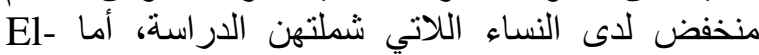
Sayed and Abdel Megeid (2013) دراسة هدفت إلى تحديد مستوى المعرفة الغذائية المرتبطة

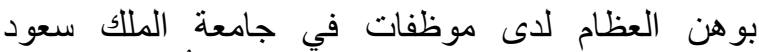

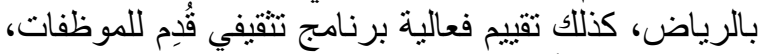

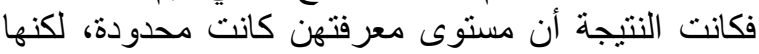
تحسنت بعد حضور البرنامج التثقيفي، كما أصبحت

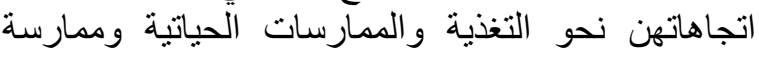
الرياضة إيجابية.

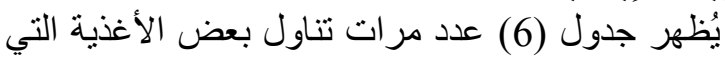

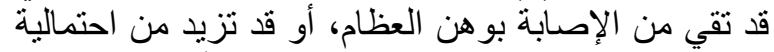

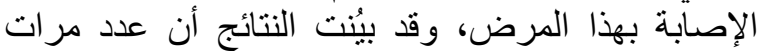

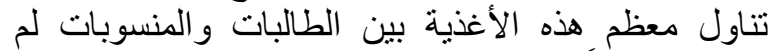

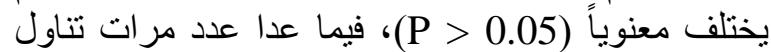

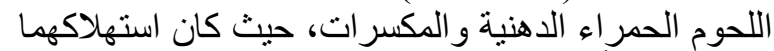

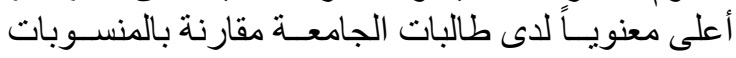

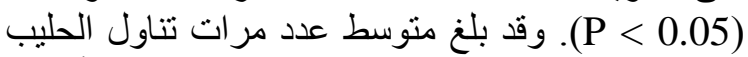

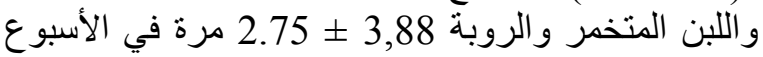

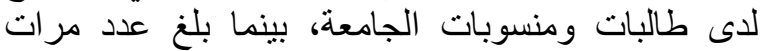
تناول الاجبان لديهن 3.82 × 2.23 مرة في الجيات الأسبوع، وقد

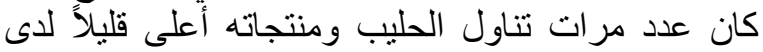

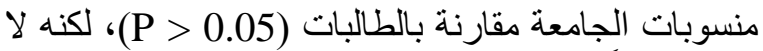

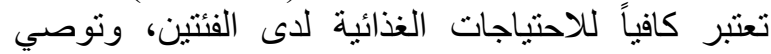
الدراسة عينة الدراسة باتباع الإرشادات التاتية الغذائية الصحيةً

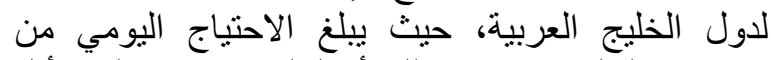

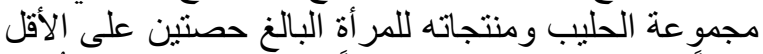

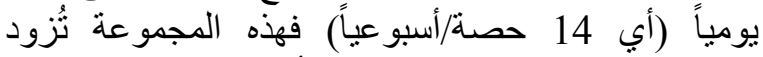

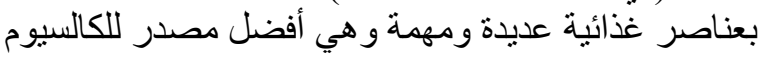
الضروري لتقوية العظام (المركز العربة العربي للتغذية، 2006)، أما متوسط عدد مرات تناول الفئ الأسماك الدهنية

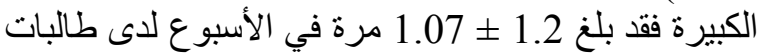

سنة، وقد بيّنت النتائج أن 80 \% من المصابات نشاطهن

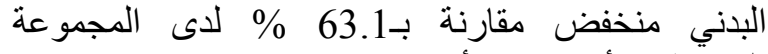
الضابطة (أصحاء). أما فقد أجروا دراسة من أهدافها تحديد

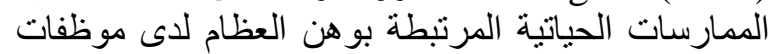

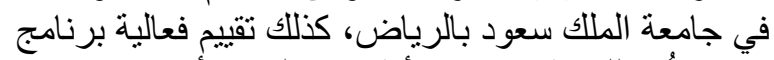

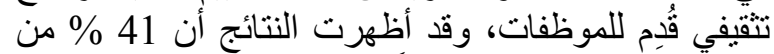

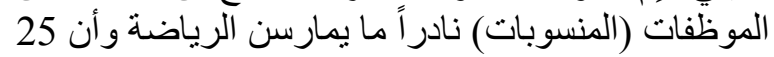

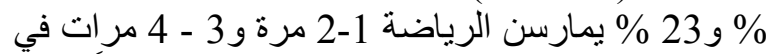

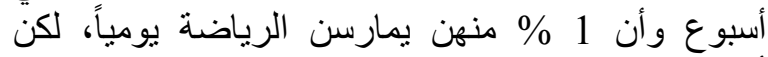

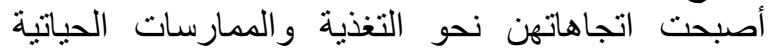

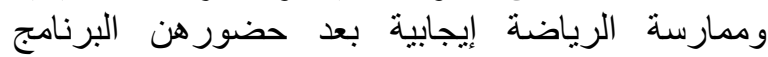

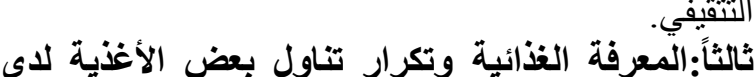
طالبات ومنسوبات الجامعة ونكانة

أظهرت النتائج في الجذوبات الجامعة (5) أن مستوى المعرفة

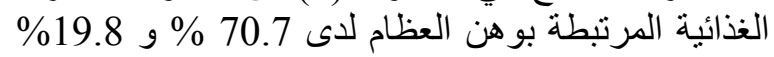

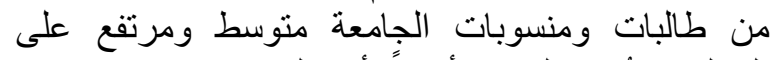

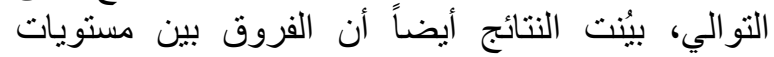

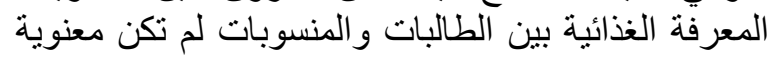

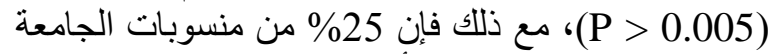

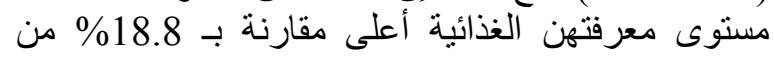

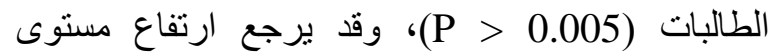

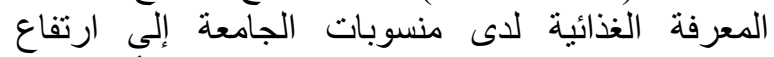

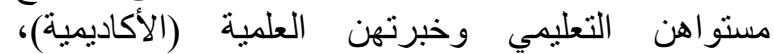

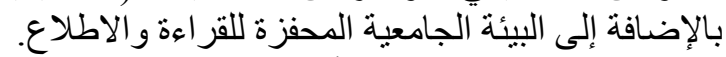

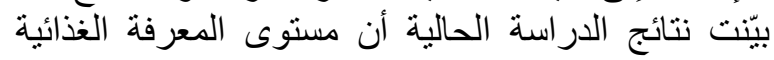

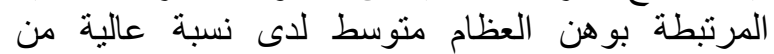

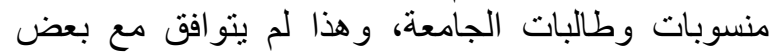

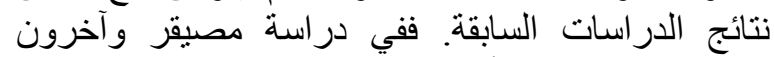

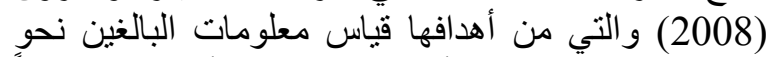

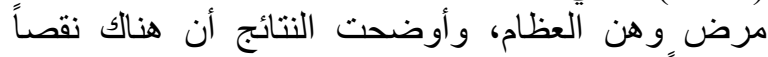
ملحوظاً في المعلومات المتعلقة بعو امل الخطورة للإصابة لنّابة

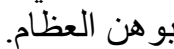

جدول (5): درجة ومستوى المعرفة الغذائية (المرتبطة بوهن العظام) لطالبات ومنسوبات الجامعة.

\begin{tabular}{|c|c|c|c|c|c|c|}
\hline \multicolumn{2}{|c|}{ 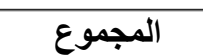 } & \multicolumn{2}{|c|}{ المنسوبات } & \multicolumn{2}{|c|}{ الطالبات } & \multirow{2}{*}{ مستوى المعرفة الغذائية } \\
\hline عدد & $\%$ & عدد & عدد & $\%$ & عدد & \\
\hline 9.5 & 58 & 6.0 & 6 & 10.2 & 52 & مستوى معرفة غذائية منخفض \\
\hline 70.7 & 431 & 69.0 & 69 & 71.0 & 362 & مستوى معرفة غذائية متوسط \\
\hline 19.8 & 121 & 25.0 & 25 & 18.8 & 96 & مستوى معرفة غذائية مرتفع \\
\hline 100 & 610 & 100 & 100 & $\mathbf{1 0 0}$ & 510 & المجموع \\
\hline \multicolumn{2}{|c|}{$1.46 \pm 7.34$} & \multicolumn{2}{|c|}{$1.38 \pm 7.55$} & \multicolumn{2}{|c|}{$1.47 \pm 7.30$} & درجة المعرفة الغذائية (متوسط \pm انحر اف معياري) \\
\hline
\end{tabular}

\# الفروق بين الطالبات والمنسوبات غير معنوية (P.05) 
2 - 4 حصة في اليوم (المركز العربي للتغذية، 2006ب ؛ الإب ؛

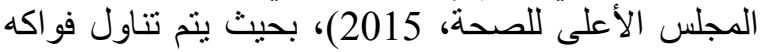

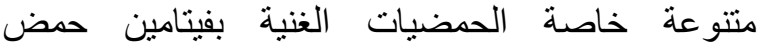

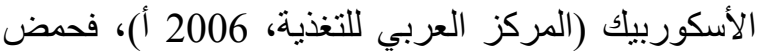

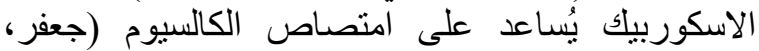
2001 ؛ المدني، 2004).

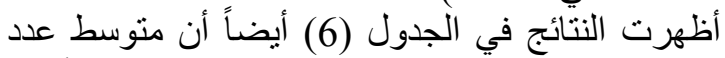

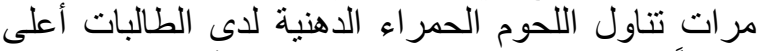

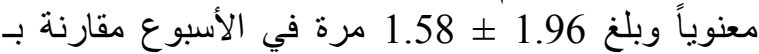

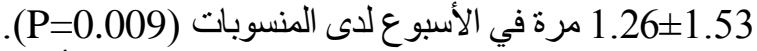

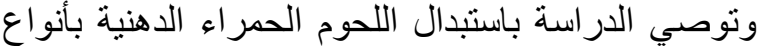

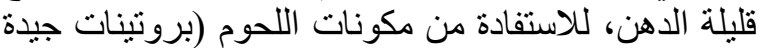
وفيتامينات ومعادن) بدون كميات عالية من من الدئن الدون

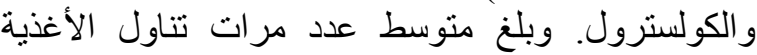

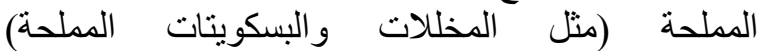

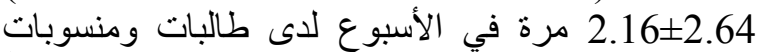

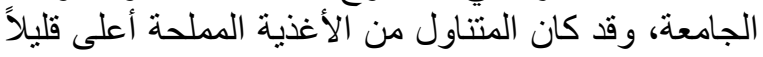

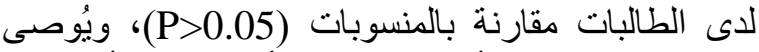

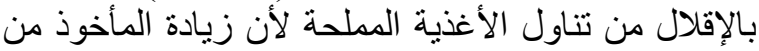

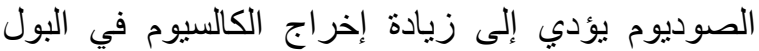

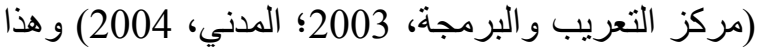
يزيد من خطر الإصابة بوهن العظام (صليبا، 2002)، أما 2004 العا

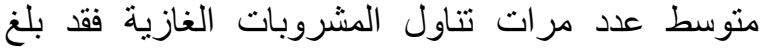

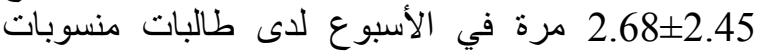

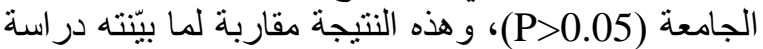
سابقة أجرتها العباد (2012) حيث أظهرت النهات أن طالبات

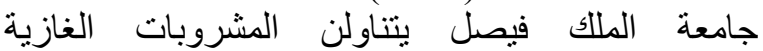

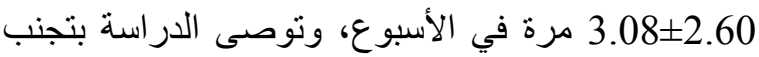

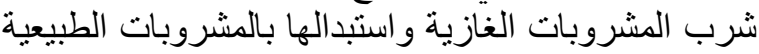

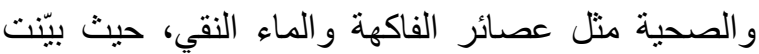

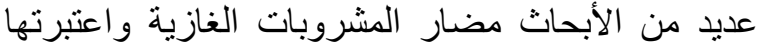
إحدى عو امل الخطر للإصابة بوهن العظام ( Mahmood لاحتوالها 2008 et al., لاحتو ائها على كمية عالية من الفوسفات (مركز التعريب الإبي والبرمجة، 2003) الذي يزيد من إلية إخر اج الكالسيوم في

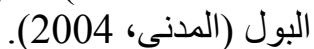

وبشكل عام أوضحت النتائج في الجدول (6) أن عدد الندان

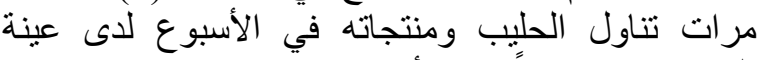

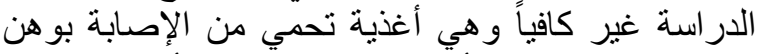

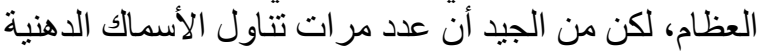

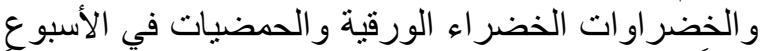
كافياً فهي أغذية تقي من هذا المرض، بيّنت الترات النتائج أيضاً

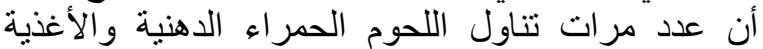

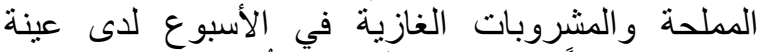

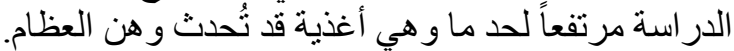

ومنسوبات الجامعة، بينما بلغ عدد مرات تناول الأسماك

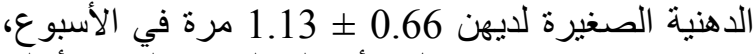
وقد كان عدد مرات تناول الأسماك الدهنية الكبيرة أعلى الألى الألى

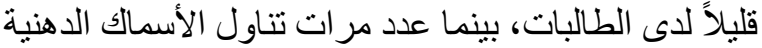

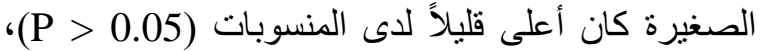

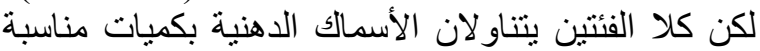

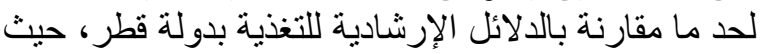

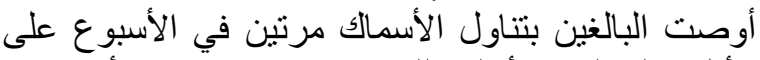

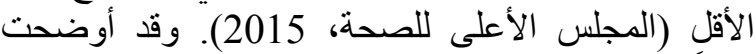
عدداً من الأبحاث أهمية استهلاك الأسماك الدهنية الدهنية للوقاية

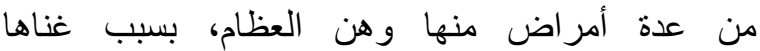
بالأحماض الدهنية طويلة السلسلة و عديدة عدم التشبع من

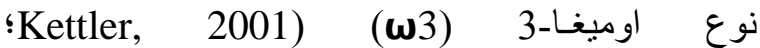
؛ Matsushita et al., 2008 ! Simopoulos, 2006

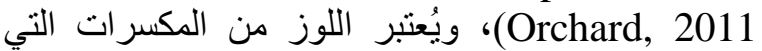

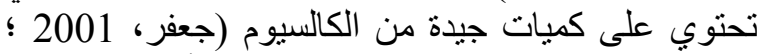

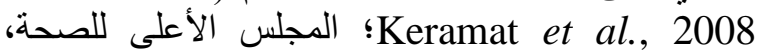

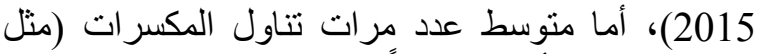

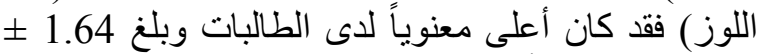

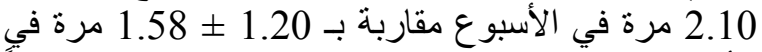

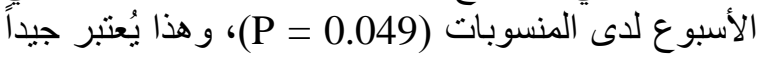

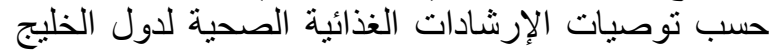

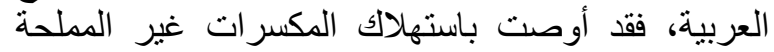

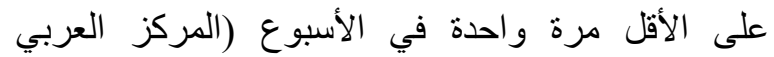

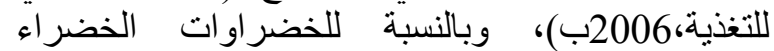

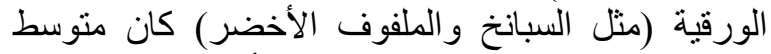

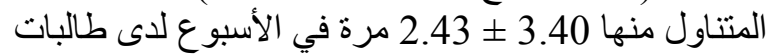

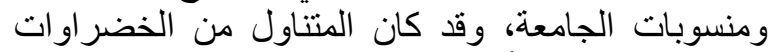

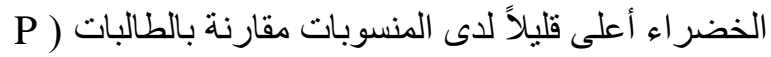

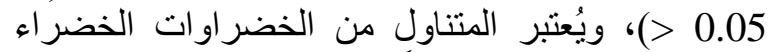

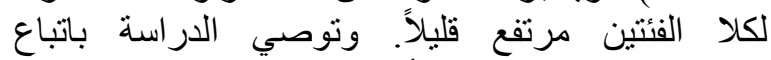
الإرشادات الغذائية والتي أوصت بتناول 3 حصص من الأن الأن

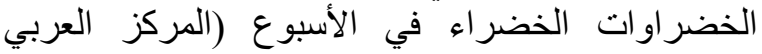
للتنذية، 2006) فالخضر اوات الخضر الاء فعالة في حماية

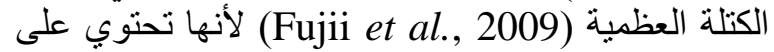

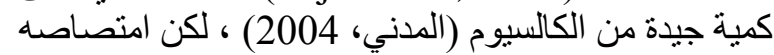

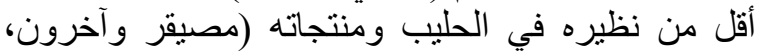

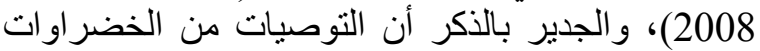
بأنواعها المختلفة تبلغ 3-5 حصة النئ في اليوم (المركز

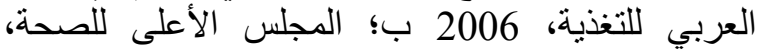

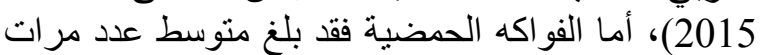

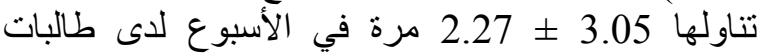

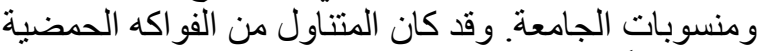

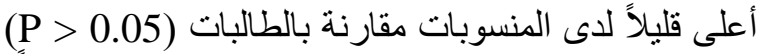
ويُعتبر المتناول من الفو اكه الحمضية لكلا الفيتنين مناسباً، أما التوصيات من مجمو عنة الفاكهة بأنو اعها المختلفة فهي لفئ 
جدول (6) : عدد مرات تتاول بعض الأغذية لاى طالبات ومنسويات الجامعة (مرة/ أسبوعياً).

\begin{tabular}{|c|c|c|c|c|c|}
\hline مستوى المعنوية & قيمة ت & المجموع & المنسويات & الطالبات & 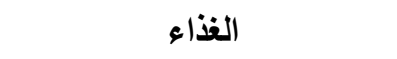 \\
\hline 0.677 & 0.416 & $2.75 \pm 3.88$ & $2.62 \pm 3.99$ & $2.78 \pm 3.86$ & الحليب واللبن المتخمر والزيادي \\
\hline 0.071 & 1.806 & $2.23 \pm 3.82$ & $2.16 \pm 4.19$ & $2.25 \pm 3.75$ & الأجبان \\
\hline 0.128 & 1.525 & $1.07 \pm 1.20$ & $0.90 \pm 1.06$ & $1.10 \pm 1.23$ & الأسماك الدهنية الكبيرة \\
\hline 0.737 & 0.336 & $1.13 \pm 0.66$ & $1.11 \pm 0.70$ & $1.14 \pm 0.66$ & الأسماك الدهنية الصغيرة \\
\hline$* 0.009$ & 2.625 & $1.54 \pm 1.89$ & $1.26 \pm 1.53$ & $1.58 \pm 1.96$ & اللحوم الحمراء الدهنية \\
\hline$* 0.049$ & 1.968 & $2.03 \pm 1.57$ & $1.58 \pm 1.20$ & $2.10 \pm 1.64$ & المكسرات (مثل اللوز) \\
\hline 0.134 & 1.500 & $2.43 \pm 3.40$ & $2.61 \pm 3.37$ & $2.39 \pm 3.33$ & الخضراوات الخضراء الورقية \\
\hline 0.315 & 1.006 & $2.27 \pm 3.05$ & $2.29 \pm 3.26$ & $2.27 \pm 3.01$ & القواكه الحمضية \\
\hline 0.194 & 1.301 & $2.16 \pm 2.64$ & $2.06 \pm 2.38$ & $2.17 \pm 2.69$ & الأغذية المملحة \\
\hline 0.148 & 1.450 & $2.68 \pm 2.45$ & $2.63 \pm 2.09$ & $2.69 \pm 2.51$ & المشرويات الغازية \\
\hline
\end{tabular}

منهن يتناولن الخضروات يومياً، بينما 28.5 \% م بتناولن

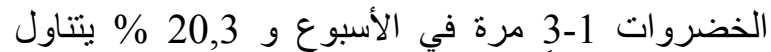

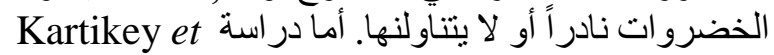

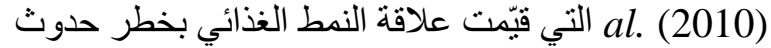

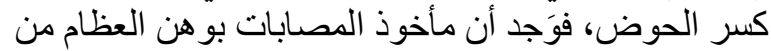
الحليب ومنتجاته و الخضرو ات وات و الفاكهة و البقول و الأسماك كان أقل مقارنة بالمجمو عة الضابطة (سليمات)، و واعتبرت

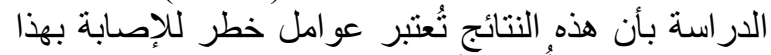

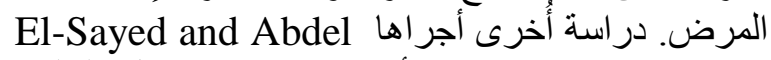
بيّت أن عدد مرات تناول الحليب

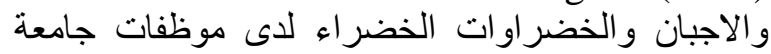

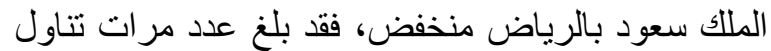
هذه الأغذية 1 - 2 مرة في الأسبوع لدى لـ 44 \% و و 38 \% \%

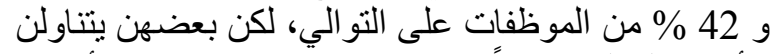

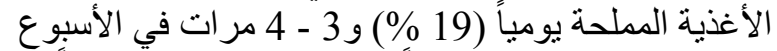

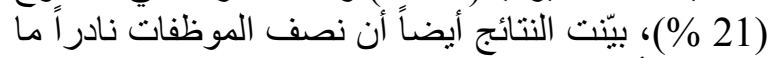

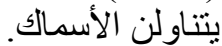
أظهر جدول (7) أن عدد مرات تناول الأغدية الغية لم يختلف

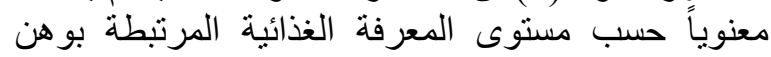

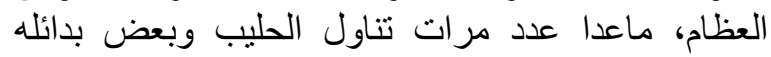

تو افقت بعض نتائج الدر اسة مع نتائج الدر اسات السابقة وبعضها لم يتو افق، منها دراسة العباد (2007) الته التي

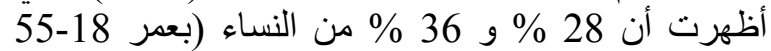

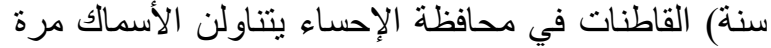
واحدة و2 - 3 مرات في الأسبوع على التيو الي، أما بالنسبة التية

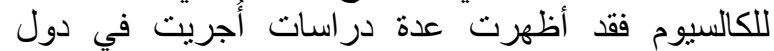

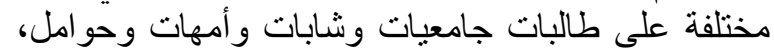

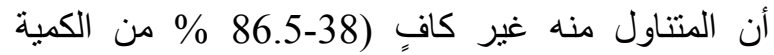

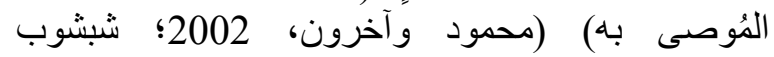

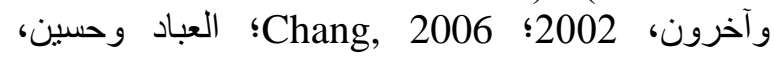
،(Fujii et al., 2009 ؛ Rafraf et al., 2009 2008 أما در اسة (2008). Mahmood et al فقد بيّنت أن تناول

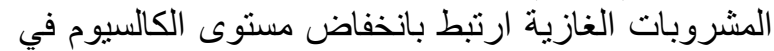

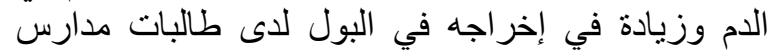

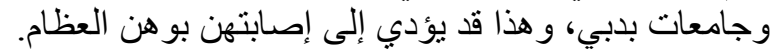

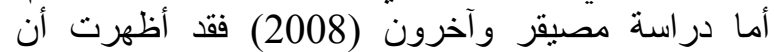
النساء البحرانيات اللاتي بعر الحليب و الجبن و اللبن المتخمر (العيران) يومياً (30.1 \%

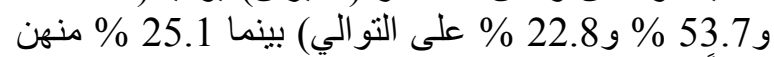
نادراً ما يشربن الحليب أو لايشربنه، كما أن 40.7 \%

جدول (7): عدد مرات تناول بعض الأغذية حسب مستوى المعرفة الغذائية (مرة/ أسبوعياً).

\begin{tabular}{|c|c|c|c|c|c|}
\hline المعنوية & قيمة ت & مستوى معرفة غذائية & مستوى معرفة غذائية & مستوى معرفة غذائية & 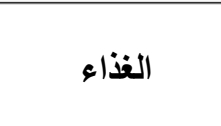 \\
\hline 0.037 & 3.309 & $3.34 \pm 4.33$ & $2.64 \pm 3.84$ & $1.99 \pm 3.22$ & المتخمر والزياديب واللبن \\
\hline 0.006 & 5.084 & $1.49 \pm 1.97$ & $1.59 \pm 1.95$ & $1.10 \pm 1.29$ & اللحوم الحمراء \\
\hline
\end{tabular}

|لمتوسط 土 الانحراف المعياري. 


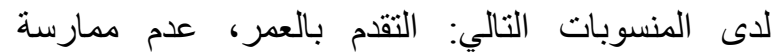

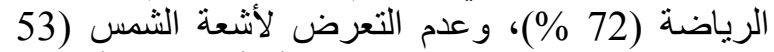

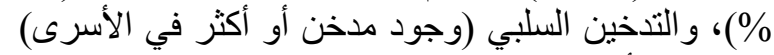

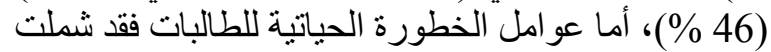
التالي: عدم ممارسة الرياضة (62.4 \% \%) و التدخين السلبي

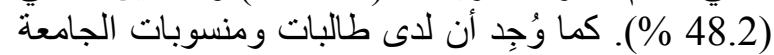

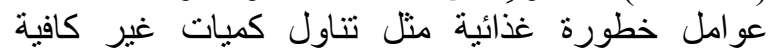
لاحتياجاتهن الغذائية من الحليب ومنتجاتهانية وتنتاول كميات

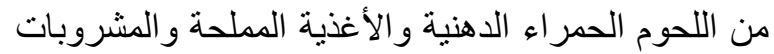

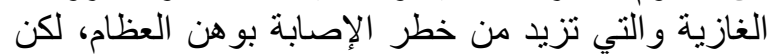

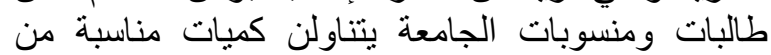

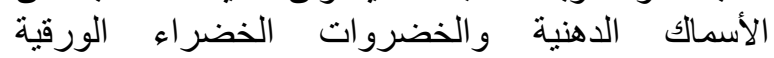
و الحمضيات و المكسر ات المهمة للوقاية من و هن العظام.

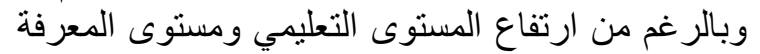

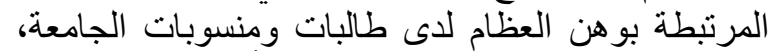

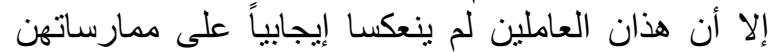
الغذائية و الحياتية المرتبطة بو هن العظام، وقد يكون السبب العبان

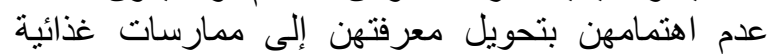

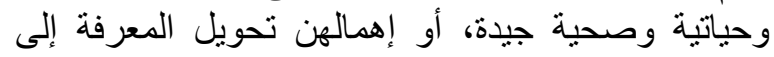

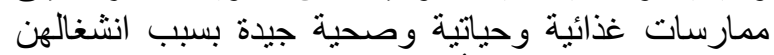

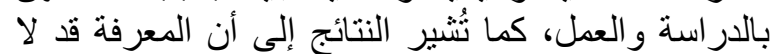

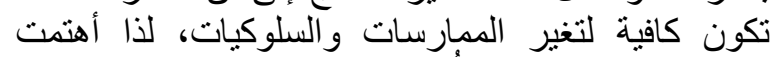

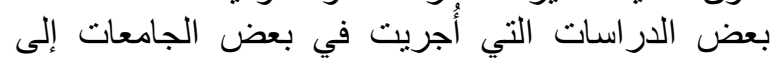
تقديم بعض برامج التنقيف الغذائي بهدف نشجيع الطلاب التهاب

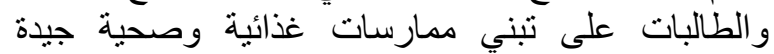

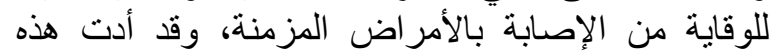

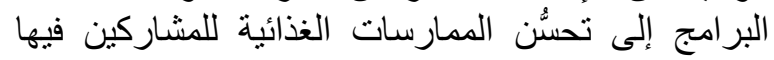
؛Dillinger, 2012؛ Shive and Morris, 2006) McKinney,2013؛ Brown, 2013,Shodunke, 2014 ؛ Naghashpour et al., 2014)، كما اقترحت بعض الحض الدراسات تصميم بعض بر امج التتقيف الغذائي الحاسوبية

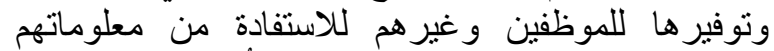

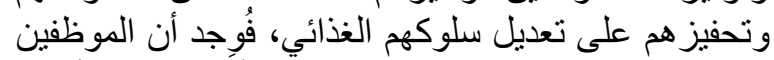

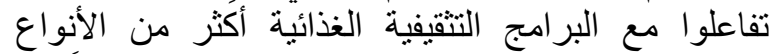

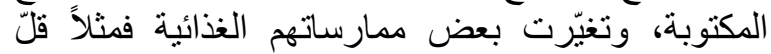
استهلاكهم للاهون وز اد استهلاكهم من الخضار التهار و الفاكهة،

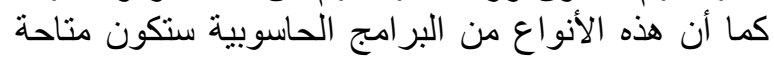

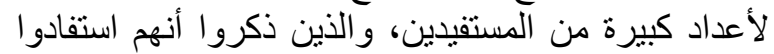

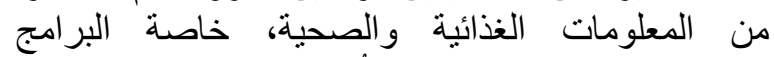

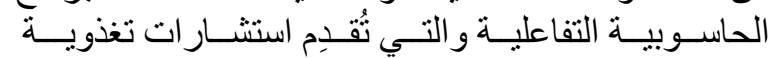

.(Block et al., 2000 ؛ Brug, 1999؛ Bung et al., 1996)

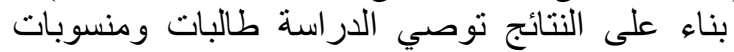

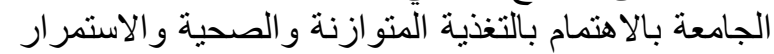
بتناول كميات كافية من الأغذية التي تقي من الإنية الإصابة

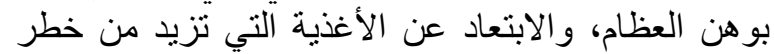

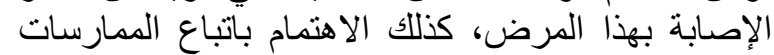

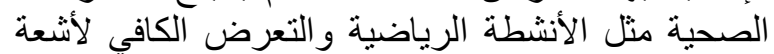

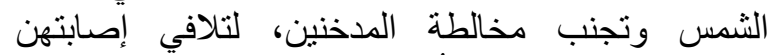

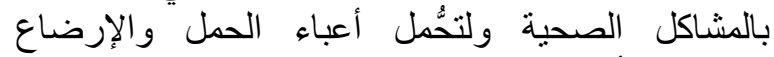
باعتبار هن أمهات المستقبل، كما يُقتترح على إدلى إدارة الجامعة
المتخمرة واللحوم الحمر اء، حيث زاد المتناول من هذه الدئ الأغذية بزيادة مستوى المعرفة الغذائية (205 )

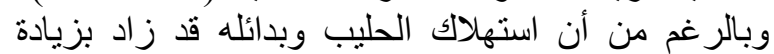
المعرفة الغذائية، إلا أن تناوله منخفض الئ لإن الدى جميع الفئات،

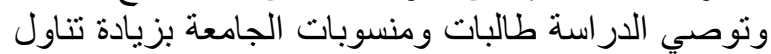

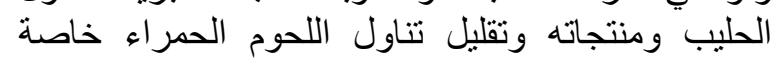
الأنو اع الاسمة. أظهرت النتائج في الجدول (8) أن هناك علاقة معنوية

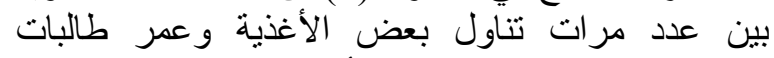

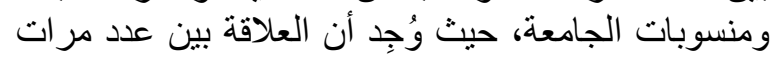

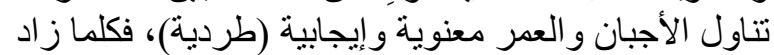

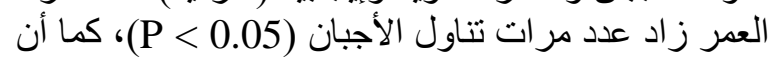

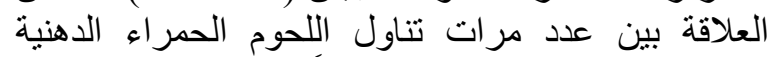

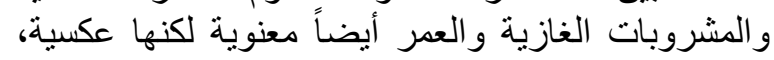

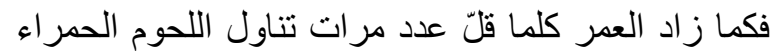
الدهنية و المشروبات الغازية (P

\begin{tabular}{|c|c|c|}
\hline مستوى المعنوية & معامل ارتباط & الغذاء أ \\
\hline 0.045 & 0.081 & الأجبان \\
\hline 0.050 & $0.079-$ & اللحوم الحمراء الدهنية \\
\hline 0.007 & $0.109-$ & المشرويات الغازية \\
\hline
\end{tabular}

تُشير النتائج في الجدول (8) بأنه مع زيادة العمر

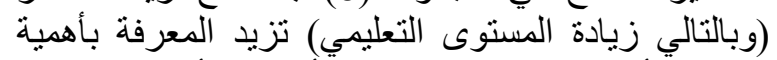

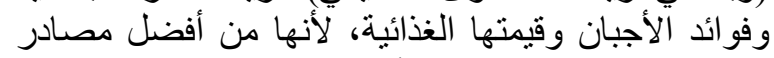

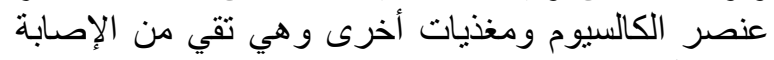
بو هن العظام

(Keramat et al., 2008 ؛ Kartikey et al., 2010 ؛ El-Sayed and Abdel Megeid, 2013)،

كما أن زيادة العمر تزيد المعرفة بأضرار المشروبات

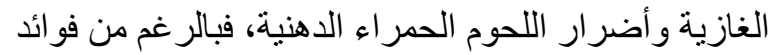

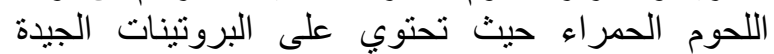

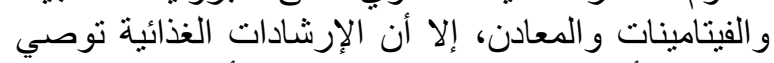

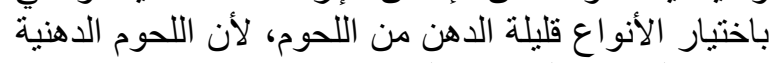

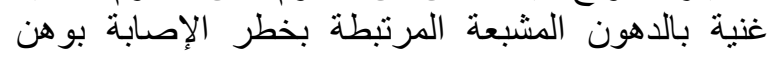

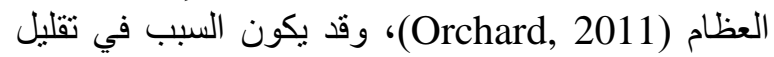

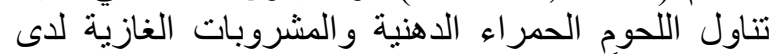

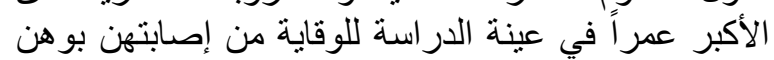

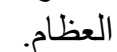
يُُستخلص من النتائج أن لدى منسوبات وطالبات جامعة

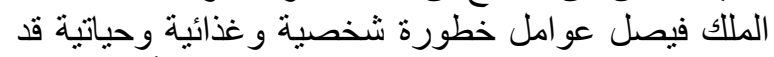

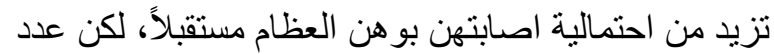

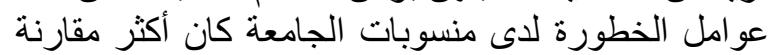

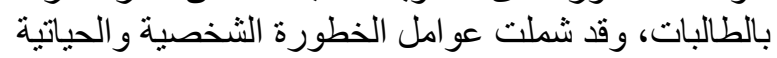


المجلة العربية للغذاء والتغذية، 5 (11): 116.125

المجلس الأعلى للصحة. (2015). الدلائل الإرشادية للتغذية بدولة قطر. إدارة الصحة العامة. الدوحة، الأركادة قطر.

المحمادي، عو اطف مسلّمّ. (2009). تأثير دقيق الصويا على بعض المؤشرات الحيوية للفئران المستأصلة

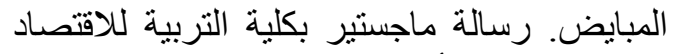

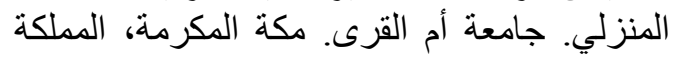
العربيةٌ السعودية. محمد، غادة و عبد الناصر، إيمان. (2014). هشانشة العظام تهدد الصحة بصمت. مجلة أسيوط للاراسات البيئة،

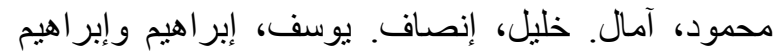

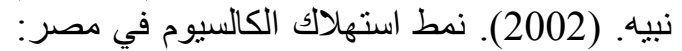

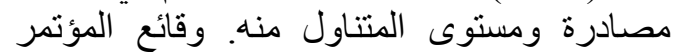
العربي الأول للتغذية، في الفترة 25 - 27 / لونئن 9 /2001 في البحرين، المجلة العربية للغذاء العزية و التغذية، 3 (6): 111 - 1121 - 12002.

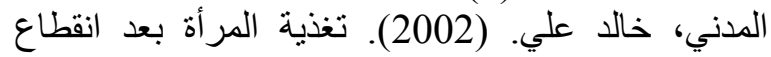

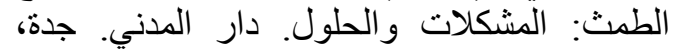
الملكة العربية السعودية.

المدني، خالد علي. (2004). هشاشة العظام: المشكلة الماتة والعلاج. دار المدني. جدة، المدية الملكة العربية

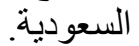

المدني، خالد علي. (2005). التغذية خلال مر احل الحياة. دار المدني. جدة، الملكة العربية السعودية.

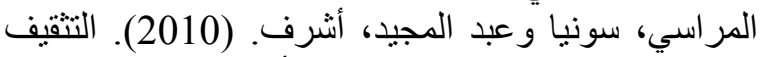
التغذائي. دار الفكر ، عمان، الأردن.

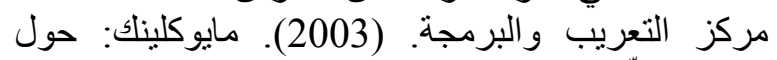

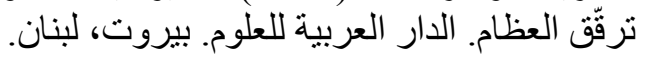

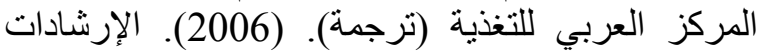
الغذائية الأمريكية (الهرم الغذائي الجديد). دار القلم. دبي، الإمارات العربية المتحدة.

المركز العربي للتغذية. (2006). الإرشادات الغذائية لإنية

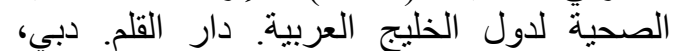
الإمار ات العربية المتحدة.

مصيقر، عبد الرحمن. المسكري، الجولندا. اللواتي، حسن.

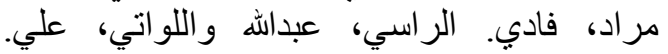

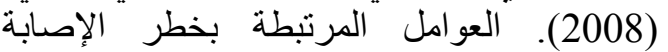
بهشاشة العظام عند البالغين في مملكة البحرين. المجلة العربية للغذاء و التغذية، 9 (19): 49 - 49 - 62. منعم، زينب (ترجمة). (2013). هثانشة العظام. مدينة الملك عبد العزيز للعلوم و التقنية. الرياض، المبنة المملكة

$$
\text { العربية السعودية. }
$$

الهزاع، هزاع محمد. (2004). النشاط البدني في مجابهة النهاية

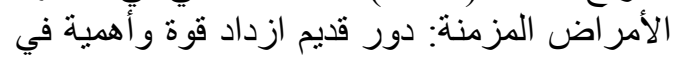

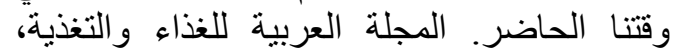

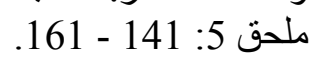

تنظيم برامج تتقيف غذائي فعالة وتفاعلية، بهدف زيادة و وعي الطالبات بأهمية التغذية الجيدة و الممارسات الصحاتية الصحية،

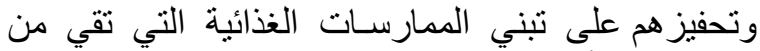
الإصـابة بالأمر اض اضئ المزمنة. شكر وتقدير

تتقام الباحثة بالثكر و التقدير لكل من قدم لها مساعدة في إنجاز البحث، وفي مقدمتهن والبفن الطالبات اللاتي ساعدن

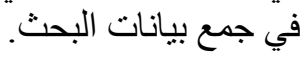

\section{4 ـ المراجع العربية}

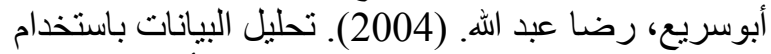

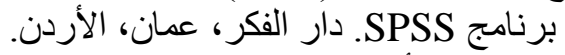

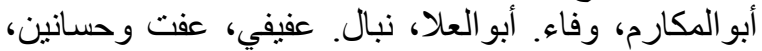

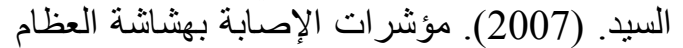
في المراهقين والبالغين المصرينين. الغذاء والتينة التغذية في الوطن العربي، وقائع المؤتمر العربي الثين الثالث الثرائ

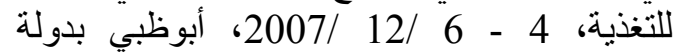

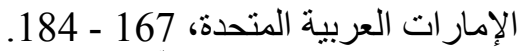

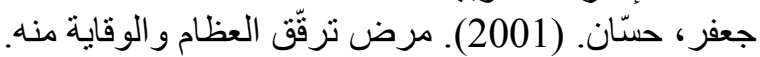
دار الحرف العربي. بيروت، لبنئ تينان.

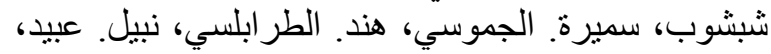
عبد المجيد. المهيري، إقبال ورجب، المبل، كاميليا.

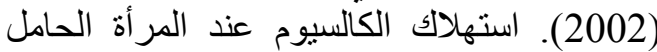

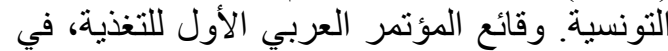

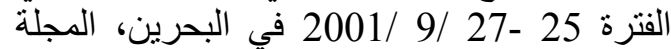
العربية للغذاء و التغذية، 3 (6): 104 - 1004 - 110. صليبا، جولي (ترجمة). (2002). ترفّق العظام. أكاديميا انترنانشونال. بيروت، لينان.

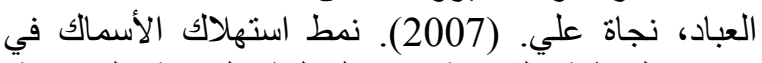
المنطقة الثرقية في المملكة العربية السعودية. المجلة العربية للغذاء و التغذية، 8 (17): 38 - 38 - 60 التئة العباد، نجاة علي وحسين، شادية محمود. (2008).

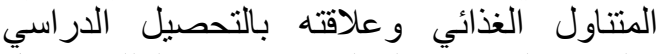
و الذكاء الوجداني لطالبات جامعة الملك فيصل بلانل

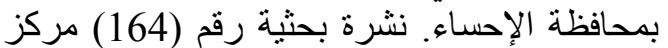

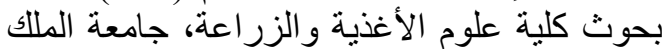
سعود، 5 - 43. العباد، نجاة علي. (2012). عادودات استهلاك الوجبات

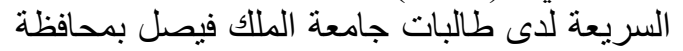
الإحساء، شرق المملكة العربية السعودية. مجلة الزية المنوفية للبحوث الزر اعية، 37 (3): 539 - 555.

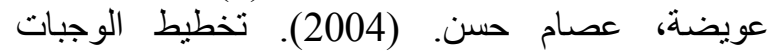
الغذائية. مكتبة العبيكان. الرياض، المملكة العربية

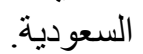
فرحات، تغريد. الاسوقي، ربيع. الشرقاوي، شريف وبدر،

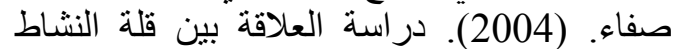
البدني و التناخين كعو امل للاختطار لحدوث هناثنة

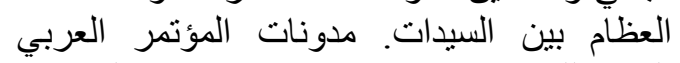
الثاني للتغذية 7 - 9 / 12/ 2004، البندرين. 


\section{REFERENCES}

Al-Shahrani F., Al-Zahran A. and Al-Haquawi A. (2010). Knowledge of osteopor-osis in middle age and eldery women. Saudi Med. J., 31 (6): 684 -687.

Alwahhabi BK. (2015). Osteoporosis in Saudi Arabia: Are we doing enough?. Saudi Med. J. 36: 1149-1150.

Aynaci O., Kerimogl S., Ozturk C. and Saracoglu, M. (2008). Bilateral nontraumatic acetabular and femoral neck fractures due to pregnancy-associated osteoporosis. Arch. Orthop. Trauma Surg., 128: 313 - 316.

Block G., Miller M., Harnack L., Kayman S., Mandel S. and Cristofar,S. (2000). An Ineractive CD-ROM for nutrition screening and counseling. Amer. J. Public Health, 90: $781-785$.

Brown K. N. (2013). Nutrition education to minimize health risk: Approaches for teaching college students and female high school athletes. (Thesis). Utah State University, USA .

Brug J., Steenhuis I., Assema P. and Vein H. (1996). The Impact of a computer-tailored nutrition intervention. Prevent. Medi. 25: $236-242$.

Brug J. (1999). Dutch research into the development and impact of computertailored nutrition education. Euro. J. Clini. Nutr., 53 (Suppl 2): S78 - S82.

Chang S. (2006). Across-sectional survey of calcium intake in relation to knowledge of osteoporosis and beliefs in young and adult women. Int'1. J. Nurs. Pract. 12: 21 27.

Cohen A. and Roe F. (2000). Review of risk factors for osteoporosis with particular reference to a possible etiological role of dietary salt. Food and Chem. Toxico., 38: $237-253$.

Daniel M., Martin A. and Faiman C. (1992). Sex hormones and adipose tissue premenopausal cigarette smokers. Int $\mathbf{J}$ Obes. 16: 245 - 254.

Davey M. R., De Villier J. T., Lipschitz S. and Pettifor, J.M. (2012). Pregnancy and lactation-associated osteoporosis. JEMDSA. 17 (3): 149 - 153.

Di Gregorio S., Danilowicz K., Rubin Z. and Mautalen, C. (2000). Osteoporosis with vertebral fractures associated with pregnancy and lactation. Nutr. 16: 1052 1055.
Dillinger D. P. (2012). A guide to acquiring healthy nutrition and fitness habits for college students: preventing diabetes, hypertension, coronary heart disease and stroke. (Thesis). Wright State Univ. USA.

Dursun N., Akin S., Dursun E., Sade I. and Korkusuz F. (2006). Influence of duration of total breast-feeding on bone mineral density in a Turkish population: does the priority of risk factors differ from society to society? Osteoporos Int'l. 17: 651- 655.

El-Sayed M. and Abdel Megeid F. (2013). Osteoporosis-related life habits, knowledge and attitude among group of female employees in King Saud University. World Appl. Sci. J. 22 (7): 919 - 925.

Fujii H., Noda T., Sairenchi T. and Muto T. (2009). Daily intake of green and yellow vegetables is effective for maintaining bone mass in young women. Tohoku J. Exp. Med., 218 (2); 149-154.

Grimes J. and Wimalawansa S. (2003). Breastfeeding and postmenopausal osteoporosis. Curr. Women Health Rep. 3: 193-198.

Hannan M.T., Felson D.T., Dawson-Hughes B., Tucker K., Cupples L.A., Wilson, P. and Kiel, D. (2000). Risk Factors for longitudinal bone loss in elderly men and women: the Framingham osteoporosis study. J. Bone and Mineral Res. 15 (4): $710-720$.

Huang Z., Himes J.H. and McGovem G.P. (1996). Nutrition and subsequent hip fracture risk among a Nutritional Cohort of White Women. Amer. J. Epidemiology. 144 (2): 124 - 134.

Kalkwarf H. and Specker B. (2002). Bone mineral changes during pregnancy and lactation. Endocrine., 17: 49 - 53.

Kalkwarf H. (2004). Lactation and maternal bone health. Adv. Exp. Med. Biol., 554: $101-114$

Kanis J. (2002). Diagnosis of osteoporosis and assessment of fracture risk. Lancet., 359: 1929 - 1936.

Karlsson M., Ahlborg H. and Karlsson C. (2005). Maternity and bone mineral density. Acta. Orthop., 76: 2-13.

Kartikey K., Singh G., Kidyore B., Somsunder Y., Howarth P.. (2010). Association of Dietary $w-6 / w-3$ fatty acid ratio and 
inflammation with risk of hip fracture. The Open. Nutraceuticals Journal. 3: 1-5.

Keramat A., Patwardhan B., Larijani B., Chopra A., Mithal A., Chakravarty D., Adibi H. and Khosravi A. (2008). The assessment of osteoporosis risk factors in Iranian women compared with Indian women. BMC Musculoskeletal Disorders. 9: 2837.

Kettler D. (2001). Can manipulation of the ratio of essential fatty acids slow the rapid rate of postmenopausal bone loss? Alternat. Med. Rev. 6 (1): 61-77.

Kidambi S., Partington, S. and Binkley N. (2005). Low bone mass prevalence and osteoporosis risk factor assessment in African American Wisconsin women. W. M. J. 104: 59 - 65.

Kovacs C. (2005). Calcium and bone metabolism during pregnancy and lactation. J. Mammary Gland Biol. Neoplasia., 10: 105 - 118.

Mahmood M., Saleh A., Alawi F. and Ahmed E. (2008). Health effects of soda drinking in adolescent girls in United Arab Emirates. J. Crit. Care. 23 (3): 434 - 440.

Matsushita H., Barrios J.A., Shea J.E. and Miller S.C. (2008). Dietary fish oil results in a greater bone mass and bone formation indices in age ovariectomize rats. J. Bone Miner. Metab., 26: 241 - 247.

McKinney C. E. (2013). Assessment of dietary behaviors of college students participating in the health promotion program BUCS: Live Well. (Thesis). East Tennessee State University. USA.

Mithal A., Wahl D., Bonjour J., Burckhardt P., Dawson-Hughes B., Eisman J.A., ElHajjFuleihan G., Josse R.G., Lips P. and Morales-Torres J. (2009). Global vitamin D status and determinants of hypovitaminosis D. Osteoporos. Int1. 20: 1807 - 1820.

Musaiger A., Hassan A. and Obeid O. (2011). The paradox of nutrition-related diseases in the Arab Countries: the need for action. Int'l. J. Environ. Res. Public Health., 8: 3637-3671.

Naghashpour M., Shakerinejad G., Lourizadeh M., Hajinajaf S. and Jarvandi F. (2014). Nutrition education based on health belief model improves dietary calcium intake among female students junior high schools. J. Health Popul. Nutr., 32 (3): 420 - 429 .
Orchard T. (2011). Fatty acids and risk of fracture in postmenopausal women. (Thesis), Ohio State University. USA.

O`Sullivan S., Grey A., Singh R. and Reid I. (2006). Bisphosphonates in pregnancy and lactation-associated osteoporosis. Osteoporos. Int'l. 17: 1008 - 1012.

Pearson D., Kaur M., San P., Lawson N., Baker P. and Hosking D. (2004). Recovery of pregnancy mediated bone loss during lactation. Bone., 34: 570 - 578.

Rafraf M., Bazyun B. and Afsharnia F. (2009). Osteoporosis-related life habits and knowledge about osteoporosis among women in Tabriz, Iran. The Int'l Medi. J., 8 (2): 17 - 21.

Ruiz-Irastorza G., Khamashtac M. and Hughes G. (2002). Heparin and osteoporosis during pregnancy. Lupus., 11: 680 - 682.

Sadat-Ali M., All-Habdan I., Al-Mulhim A. and El-Hassan A. (2005). Effect of parity on bone mineral density among postmenopausal Saudi Arabian women. Saudi Med., J. 26 (10): 1588-1590.

Sarli M., Hakim C., Rey P. and Zanchetta J. (2005). Osteoporosis during pregnancy and lactation report of eight cases. Medicina (B. Aires) 65: 489 - 494. (Abstract).

Shive S. E. and Morris M. N. (2006). Evaluation of the Energize your life! Social marketing campaign pilot study to increase fruit intake among community college students. J. Amer. College Health., 55 (1): 33 - 39.

Shodunke A. R. (2014). Sampled university students` perceived risk of diabetes and self-reported diabetes risk factors. (Thesis). Minnesota State University, Mankato. USA.

Simopoulos A. (2006). Evolutionary aspects of diet, the omega-6/omega-3 ratio and genetic variation: nutritional implications for chronic diseases. Biomed. and Pharmacoth., 60: 502-507.

VonHurst P. and Wham, C. (2007). Attitude and knowledge about osteoporosis risk prevention: a survey of New Zealand women. Pub. Health Nutr. 10: 747-753.

Weisman S. (2005). The calcium connection to bone health across a women`s lifespan: a roundtable. J. Reprod. Med., 50: 879 884.

Whaba S., AbdEl-Shaheed A., Tawhee M., Mekkawy A. and Arrafac A. (2010). 
Osteoporosis knowledge, beliefs and behaviors among Egyptian female students. Proceeding of the $3^{r d}$ International Conference of the Arab Society for Medical research (JASMR). 12 -14 Oct. 2010, Libya. 5 (2): 173 - 180.
Yeab S.S., Goh E. M. and Das G. E. (2010). Knowledge about osteoporosis in Malaysia population. Asia Pac. J. Pubic. Health., 22 (2): 233 - 410. 